
\title{
25 Research Suare \\ Study on the Influence of Temperature on Tire Cornering Stiffness and Aligning Stiffness
}

\section{Dang Lu}

Jilin University

Lei Lu

Jilin University

HaiDong Wu ( $\square$ wuhd@jlu.edu.cn )

Jilin University

Lun Li

General R\&D Institute of China Department Expertment Unit China FAW Group Co. LTD

Wei Wang

General R\&D Institute of China Department Experiment Unit. China FAW Group Co.. LTD

ManYi Lv

First Automobile Works Group Corporation Research and Development Center

Original Article

Keywords: tire temperature model, cornering stiffness, aligning

Posted Date: June 26th, 2020

DOI: https://doi.org/10.21203/rs.3.rs-37902/v1

License: (c) (i) This work is licensed under a Creative Commons Attribution 4.0 International License.

Read Full License 


\section{Title page}

\section{Study on the Influence of Temperature on Tire Cornering Stiffness and Aligning Stiffness}

Dang Lu, born in 1972, received a Ph.D. degree in vehicle engineering from Jilin University in June 2003. He is a professor of Jilin University. From March 2008 to June 2009, he worked as a visiting scholar at the General Motors North American R\&D Center. He is currently the director of the Tire Mechanics Research Office of Jilin University. Mainly engaged in nonlinear tire dynamics theory, testing and applied research.

Tel: +86-13504704159; E-mail: ludang@jlu.edu.cn

Lei Lu, was born in Shijiazhuang, Hebei Province, China in 1989. He received a master's degree in vehicle engineering from Jilin University in 2017. He is pursuing a doctoral degree in vehicle engineering from Jilin University. His main research interests are tire dynamics and indoor-outdoor consistency of tire mechanical properties.

Tel: +86-13154391695; E-mail: ludang@jlu.edu.cn

HaiDong Wu, was born in Hebei, China in 1978. He received a Ph.D. degree in vehicle engineering from Jilin University in July 2007. $\mathrm{He}$ is an associate professor of Jilin University. From January 2012 to January 2013, he worked as a visiting scholar at Virginia Tech University. At present, the main research work includes research and application of tire dynamic model, electronic brake system and stability control of commercial vehicles and trajectory tracking control of intelligent vehicles.

E-mail: wuhd@jlu.edu.cn

Lun Li, born in March 1986, graduated with Bachelor of Jilin University of Technology in 2006 majoring in Vehicle Engineering, is a Chassis Performance Control Engineer of General R\&D Institute of China FAW.

E-mail: lilun@faw.com.cn

Wei Wang, born in March 1986, graduated with Master of Engineering from Dalian University of Technology in 2012 majoring in Vehicle Engineering, is a Chassis Performance Control Engineer of General R\&D Institute of China FAW.

E-mail: wangwei8@ faw.com.cn

Manyi Lv, born in 1987, graduated with Bachelor degree from Jilin University in 2010 majoring in Vehicle Engineering, is a Chassis Performance Control Engineer of General R\&D Institute of China FAW.

\section{Corresponding author: HaiDong Wu E-mail: wuhd@jlu.edu.cn}




\title{
ORIGINAL ARTICLE
}

\section{Study on the Influence of Temperature on Tire Cornering Stiffness and Aligning Stiffness}

\author{
Dang $\mathrm{LU}^{1} \quad$ Lei $\mathrm{LU}^{1}$ HaiDong $\mathrm{WU}^{1} \quad \mathrm{Lun} \mathrm{Li}^{2} \quad$ Wei Wang ${ }^{2} \quad{\text { Manyi } \mathrm{Lv}^{2}}^{2}$
}

\begin{abstract}
'Abstract: Based on the results of tire handling test, the cornering properties of the tire at a small range of steer angles under different temperature are obtained, and the variation law of the tire cornering characteristic parameters with the tire temperature is obtained. By establishing a tread temperature model and finite element tire model considering temperature, the mechanism of tire mechanical properties with temperature is clarified, and the expression of tread stiffness and aligning stiffness considering temperature is obtained. Then, based on the above expression and the tire brush model considering the tire temperature state, a complex brush model is established. Through the model derivation, the relationship between the temperature and the tire cornering stiffness is obtained. The relationship is used as the basic expression formula to establish the UniTire cornering model considering tire temperature. In order to verify the correctness of the model, four kinds of temperature state cornering data are used for parameter identification, and the tire cornering properties in the other two temperature states is predicted. The error between the simulation results of the prediction model and the experimental results is very small, which effectively proves the predictive ability of the UniTire cornering model considering tire temperature. This research is helpful to improve the application of UniTire model, and provide theoretical and technical support for UniTire model indoor and outdoor expansion applications
\end{abstract}

Keywords: tire temperature model; cornering stiffness; aligning

HaiDong Wu

wuhd@jlu.edu.cn

1 State Key Laboratory of Automotive Simulation and Control, Jilin University , Changchun 130025 , China

2 General R\&D Institute of China Department Experiment Unit, China FAW Group Co.,LTD, Changchun 130013 stiffness; brush tire model; UniTire model

\section{Introduction}

Tire is a rubber product, and the rubber material behaves very differently at different temperatures. There are huge distinctions of tire mechanical properties at different temperatures. Tire is the only part of the vehicle that is in contact with the road surface. The mechanical characteristics of the tire are the basis of vehicle dynamics. Studying the mechanical characteristics of the tire at different temperatures is the key to designing a vehicle with good handling stability.

Due to the viscoelastic of the rubber material, internal heat is generated for tire's deformation under the action of external force, which causes a certain change in the tire mechanical properties.

In 1998, Wei Yintao, through the finite element analysis method, calculated the steady-state deformation and stress-strain information of the tire, then calculated the energy loss and heat generation rate of the tire during the deformation process, and finally calculated the tires location temperature.

In 2002, Li Youde conducted a constant-speed rolling test of tires at different speeds based on an indoor drum test rig. During the test, a temperature measurement system was used to measure the temperature of the tire surface, and the curve of the tire surface temperature changing with time was obtained. The least square method was used to fit the test data, and the temperature 
rise model of the tire tread was initially established.

In 2003, based on the test data in [4], Li Jie constructed a mathematical model for analyzing the temperature of tire tread surface. Based on the finite element numerical calculation method, the temperature characteristics of the tire were calculated. The influence of tire speed and tire geometric parameters on tire heat generation model were studied.

In 2008, Raffaele De Rosa established a one-dimensional tire thermodynamic model to study the thermodynamic characteristics of the tire[6]. The model consists of three parts: the tire-air contact model, the footprint slip model and the footprint adhesion model. Based on the model, relevant simulations were carried out and compared with the test data.

In 2008, Pireer Fevrier and Gerard Fandard proposed the TameTire tire model [7], which consists of three parts: the tire mechanics model, the shear friction model and the temperature model. Based on the brush model, a tire mechanics model is proposed. Then the model is applied to the real-time trajectory tracking simulation of the vehicle, and the consistency level of the tire model in the real-time simulation is evaluated. From the simulation results, it can be seen that the tire pressure and temperature of the tire have a very large effect on the vehicle's handling stability.

In 2011, Masahiko established a tire dynamics model considering temperature based on the Magic Formula tire model and tire tread thermodynamic model[8]. By embedding the temperature characteristics in the $\mathrm{D}$ and $\mathrm{K}$ parameters, the Magic Formula tire model can express the lateral and longitudinal mechanical characteristics at different temperatures.

In 2012, Kelly established a brush model that considers temperature characteristics based on the relationship between rubber characteristics with temperature and rubber friction characteristics with temperature [9], The tire model includes a temperatureand frequency-dependent model of road/tire friction. A lumped parameter approach is used to model the thermodynamics of the various parts of the tire such as the tread, carcass and inflation gas. The influence of tire, track surface and ambient temperatures on time-optimal manoeuvring is presented

In 2018, Chen Ping proposed a rubber temperature rise model based on Kelly's brush model considering temperature. The temperature characteristics are introduced into the UniTire tire model, and the vehicle stability simulation is carried out based on the UniTire model[10]. But the simulation accuracy of the tire model is not been verified.

In 2018, Hyun Seok Song et al. proposed a method for predicting tire temperature distribution under rolling conditions based on the tire finite element model [11]. The frictional heat generation of the tire is based on the tangential force friction work in the tire footprint, and the internal heat generation of the tire is calculated based on the viscoelastic of the tire.

In summary, the current research on tire temperature is mainly divided into two aspects: 1 . The temperature change during the rolling process and the temperature rising model of the tire. 2.The change of the mechanical characteristics of the tire after the tire temperature changes. For the second aspect, the simplified theoretical model only considered the effect of temperature on the tread, but did not considered the effect of temperature on the carcass, and the model has not been verified.

In this paper, based on the tire corner stiffness characteristic test under different temperature conditions and the rubber dynamic thermal analysis test, the change law of tire cornering mechanical properties with temperature is obtained. Based on the rubber dynamic thermal analysis test, the rubber property changes with temperature are obtained and the tire finite element model is established to study the deformation law of the carcass and tread at different temperatures. Finally, the cornering stiffness model of UniTire model considering the influence of temperature is established, which improves the accuracy of tire dynamics simulation.

\section{Tire Cornering Test under Different Temperatures}

In this paper, the tire is first placed in an incubator equipment for several hours. After the tire temperature is completely stabilized to the set temperature, the tire corner 
stiffness test is carried out to obtain the mechanical characteristics of the tire corner stiffness at different temperatures.

\subsection{Test Condition}

The test tire type is Hankook 22555 R17. The tire cornering mechanical properties are tested under 6 different temperature conditions. In order to control the temperature of the tire during the test, this test uses a low speed test to ensure that the tire temperature does not change more than 3 ${ }^{\circ} \mathrm{C}$ during the test. The specific test content is as shown in the table 1 .

Talbe1 Test conditions under different temperatures

\begin{tabular}{c|ccccc}
\hline Brand & Temperature & Inflation & Speed & $\begin{array}{c}\text { Slip } \\
\text { Angle }\end{array}$ & $\begin{array}{c}\text { Vertical } \\
\text { Load }\end{array}$ \\
\hline \multirow{5}{*}{ ATLAS } & $0^{\circ} \mathrm{C}$ & & & & 2000 \\
& $10^{\circ} \mathrm{C}$ & & & -1, & 4000 \\
& $18^{\circ} \mathrm{C}$ & \multirow{2}{*}{$250 \mathrm{kPa}$} & $5 \mathrm{~km} / \mathrm{h}$ & $-0.5 、$ & 6000 \\
& $32^{\circ} \mathrm{C}$ & & & $0.5 、 1$ & 8000 \\
& $43^{\circ} \mathrm{C}$ & & & & 10000 \\
& $53^{\circ} \mathrm{C}$ & & & & 12000 \\
\hline
\end{tabular}

\subsection{Test Result}

The tire incubator equipment is shown in Figure 1, and the MTS CT III tire six-component force test rig is shown in Figure 2

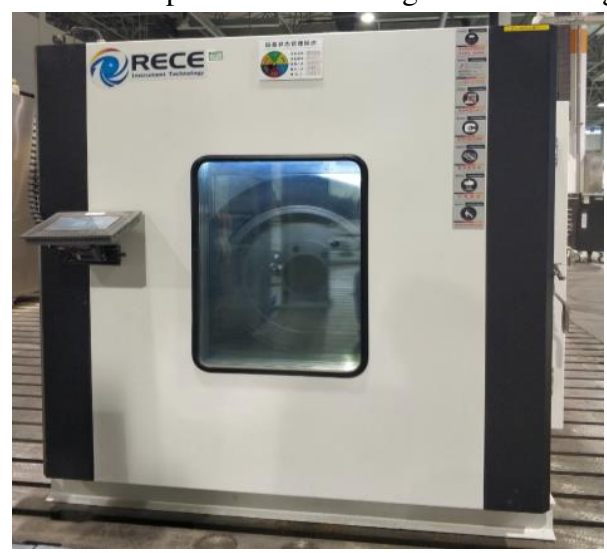

Figure 1 Tire incubator equipment

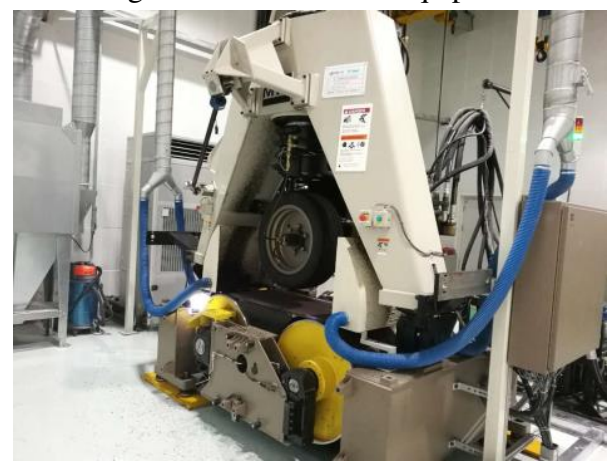

Figure 2 MTS CT III tire test rig

Under different loads and different temperatures, the tire lateral mechanical characteristics comparison curve is shown in figure 3-5
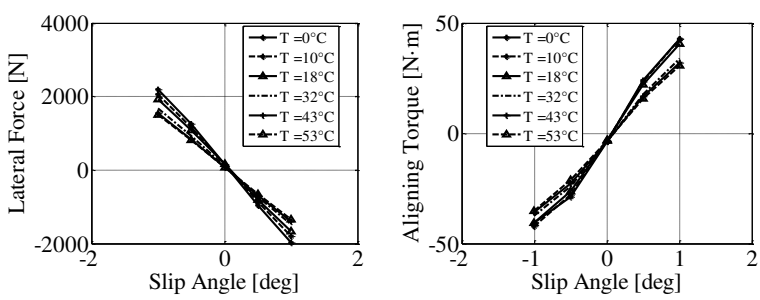

Figure 3 Comparison result of lateral force and aligning torque under different temperature at $4 \mathrm{kN}$ loads
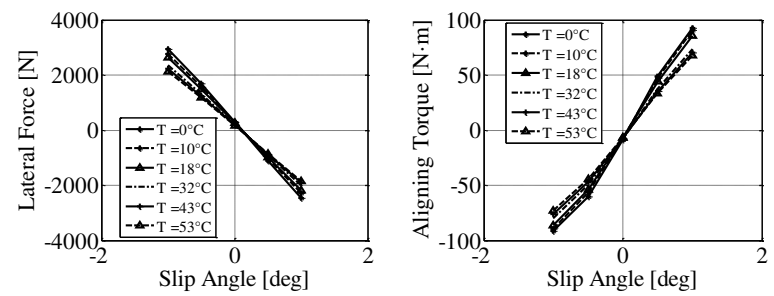

Figure 4 Comparison result of lateral force and aligning torque under different temperature at $6 \mathrm{kN}$ loads
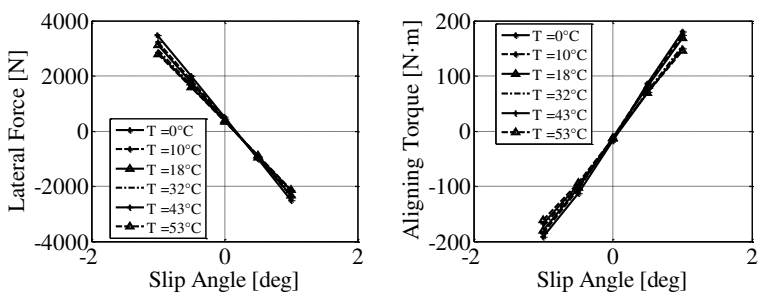

Figure 5 Comparison result of lateral force and aligning torque under different temperature at $10 \mathrm{kN}$ loads

From the test results above, it can be seen that the lateral force and the aligning torque of the tire have a large difference at different temperatures, and the key characteristics are the cornering stiffness and the aligning stiffness.

The curve of tire corner stiffness with temperature under different loads is shown in figure 6

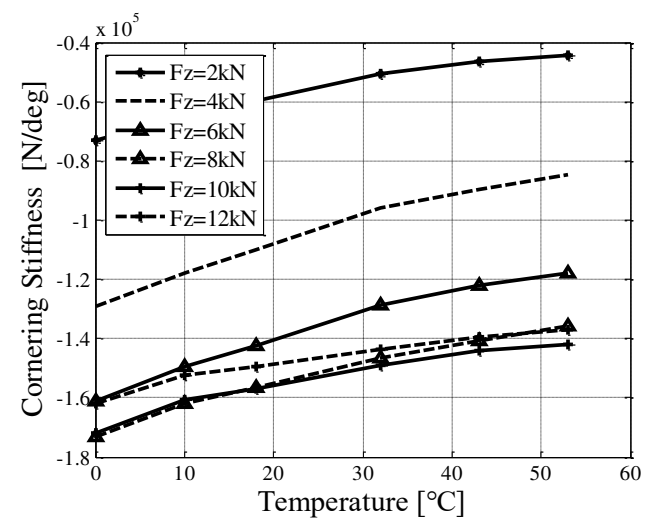

Figure 6 Variation curve of tire cornering stiffness with 
temperature under different loads

The curve of tire aligning stiffness with temperature under different loads is shown in figure 7

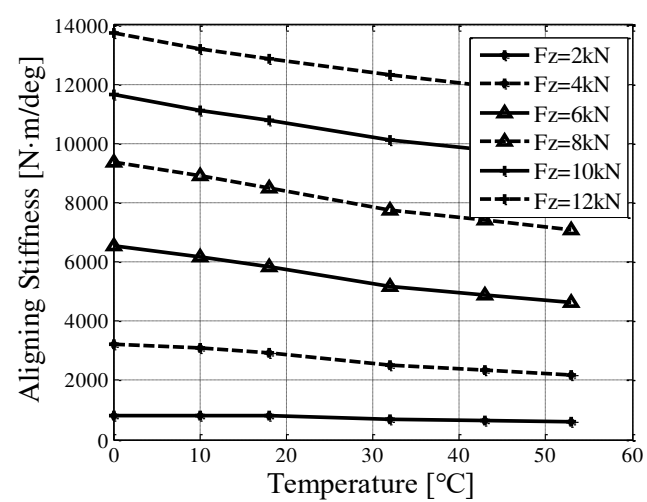

Figure 7 Variation curve of tire Aligning stiffness with temperature under different loads

As is shown in the curve of corner stiffness and aligning stiffness with temperature, the corner stiffness and the aligning stiffness of the tire gradually decreases with the increase of tire temperature under the same vertical load.

\section{Mechanism of temperature influence on tire mechanical properties}

Firstly, the rubber is subjected to dynamic mechanical analysis test and tensile test at different temperatures to obtain the variation law of rubber mechanical properties with temperature. The finite element analysis method is used to analyze the lateral and torsional deformation of the carcass at different temperatures. After that, the tire is simplified into tread and carcass parts, and the influence of temperature on the mechanical characteristics of tire tread and carcass is studied.

\subsection{Rubber dynamic mechanical analysis test under different temperatures}

A cylindrical rubber block with a diameter of $25 \mathrm{~mm}$ and a height of $13 \mathrm{~mm}$ is used for dynamic mechanical analysis and testing on a DMA testing rig. The DMA test rig is shown in Figure 8. The test result is shown in Figure 9.

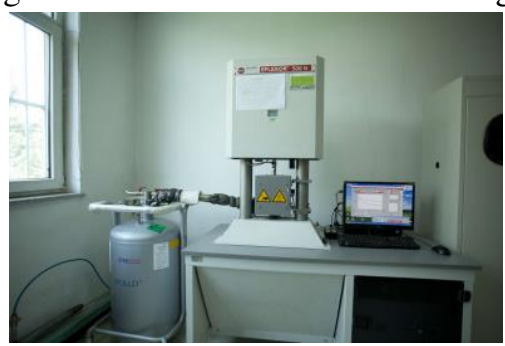

Figure8 Rubber DMA test rig

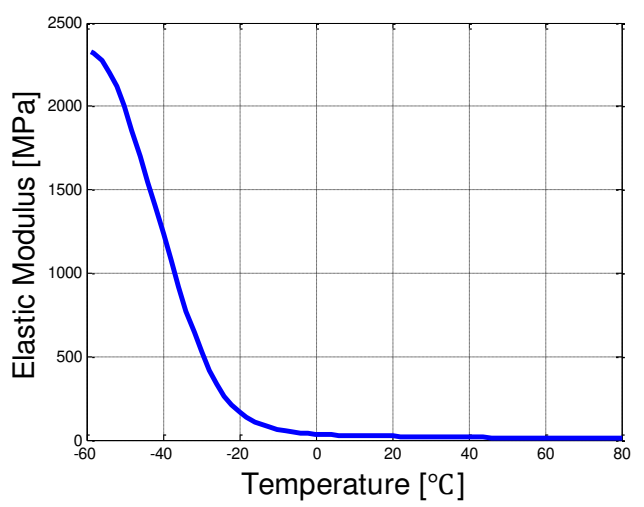

Figure 9 The elastic modulus at different temperatures

It can be seen from the test results that the elastic modulus of rubber is decreasing with increasing temperature.

It is known that the shear modulus and elastic modulus of rubber have a strong correlation[9], so the expression of the shear modulus of rubber with temperature can be approximated_as shown in equation (1):

$$
G_{\text {tread }}=\frac{K_{A}}{e^{-K_{B} \cdot T_{A}}} e^{-K_{B} \cdot T_{\text {tread }}}+G_{\text {limit }}
$$

where

$K_{A}, K_{B}, T_{A}$ is the parameters of temperature.

$G_{\text {limit }}$ is the high temperature critical modulus of

rubber material.

According to the formula (1), the relationship between the shear modulus of rubber with the temperature is obtained. Therefore, the lateral uniform stiffness of the tire tread can be obtained as shown in (2)

$$
k_{t y 0}=p_{1} \cdot G_{t r e a d}
$$

Where: $p_{1}$ is the geometric parameter of rubber.

\subsection{Effect of temperature on the mechanical properties of tire carcass}

It can be seen from the previous section that the influence of temperature on the elastic modulus of rubber, and the temperature characteristics of the tire carcass cannot be directly measured from the test, so the tire carcass characteristics with temperature are analyzed with the help of the finite element analysis method Changes with temperature.

Based on the tire finite element model used in paper[12], the tire lateral translation stiffness and torsional stiffness simulation at different temperatures are carried out 
respectively, and then the variation law of the translational stiffness and torsional stiffness of the carcass with temperature is obtained. The specific simulation conditions are shown in Table 2.

Table 2 Finite element simulation states

\begin{tabular}{|c|c|c|c|c|}
\hline $\begin{array}{c}\text { Simulation } \\
\text { conditions }\end{array}$ & $\begin{array}{c}\text { Temperature } \\
\left({ }^{\circ} \mathrm{C}\right)\end{array}$ & $\begin{array}{c}\text { Lateral } \\
\text { displacement } \\
(\mathrm{mm})\end{array}$ & $\begin{array}{c}\text { Steer } \\
\text { Angle } \\
\left({ }^{\circ}\right)\end{array}$ & $\begin{array}{c}\text { Vertical } \\
\text { load(N) }\end{array}$ \\
\hline $\begin{array}{c}\text { Torsional } \\
\text { stiffness }\end{array}$ & $\begin{array}{c}-20 、-10 、 \\
\text { 0、20、 }\end{array}$ & 0 & 2 & 2000 \\
simulation & $30 、 40$ & & & 3000 \\
\hline Lateral & $-20 、-10 、$ & & 0 & 2000 \\
stiffness & 0、20、 & 15 & & 4000 \\
simulation & $30 、 40$ & & & \\
\hline
\end{tabular}

After that, the deformation of the carcass is extracted. The method of extracting the carcass deformation is to take the displacement of the point on the midline (red dotted line) of the tire inner surface in the footprint (between the red solid lines) as the carcass deformation, as shown in Figure 10. Taking a load of $3000 \mathrm{~N}$ as an example, the deformation of the carcass is shown in Figure 11-12.

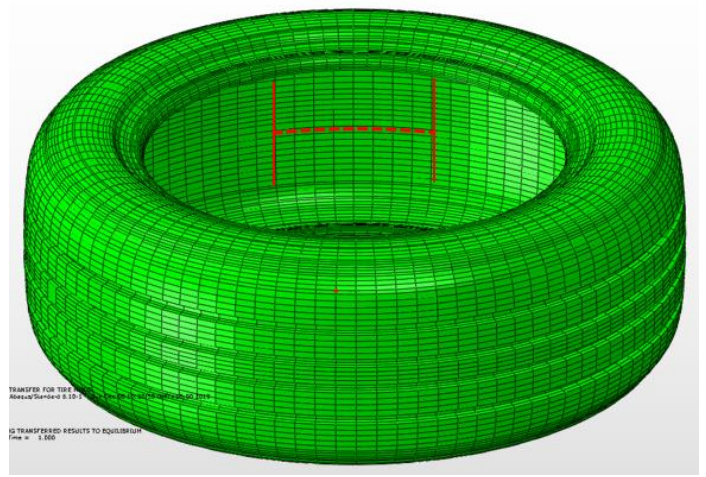

Figure 10 Node position on tire inner surface

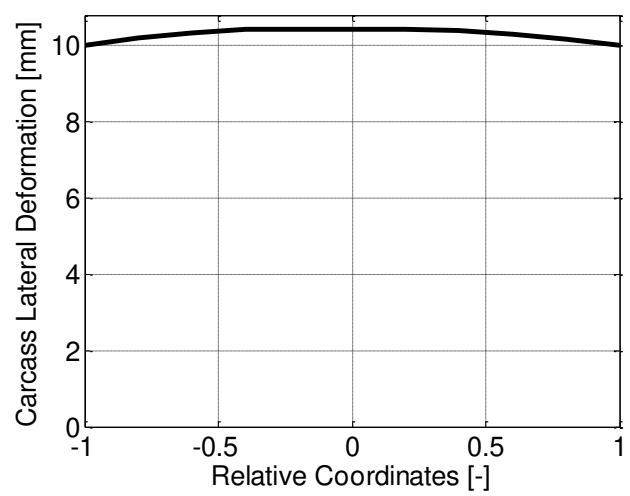

Figure11 Deformation curve of carcass under Lateral stiffness simulation

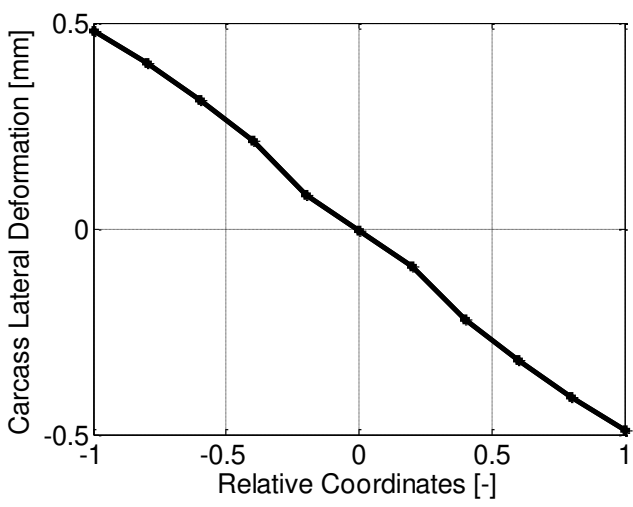

Figure 12 Deformation curve of carcass under torsional stiffness simulation

From the simulation results of lateral stiffness simulation, it can be seen that the deformation of the carcass is mainly translational deformation, and the bending deformation of the tire is not particularly significant; from the simulation results of torsional stiffness simulation, it can be seen that the deformation of the tire is mainly torsional deformation.

In the case of finite element simulation of lateral stiffness, since the carcass bending deformation component is very small, the carcass deformation is simplified into translational deformation, and the position of each coordinate point is averaged as the translational amount of the carcass; In the torsional stiffness finite element simulations, the angles of change of each position of the tire relative to the initial position are respectively solved as the torsion amount of the carcass. The variation curves of tire lateral force and aligning torque with corresponding deformation are shown in Figures 13-14.

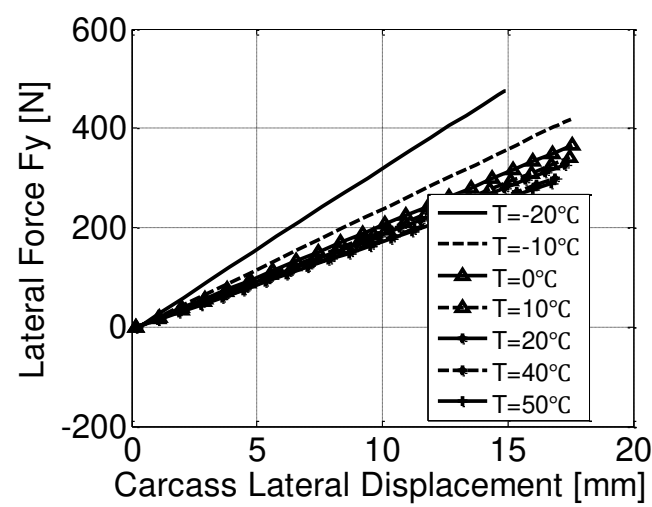

Figure 13 Lateral force of the carcass with lateral displacement at different temperatures ( Load $3000 \mathrm{~N})$ 


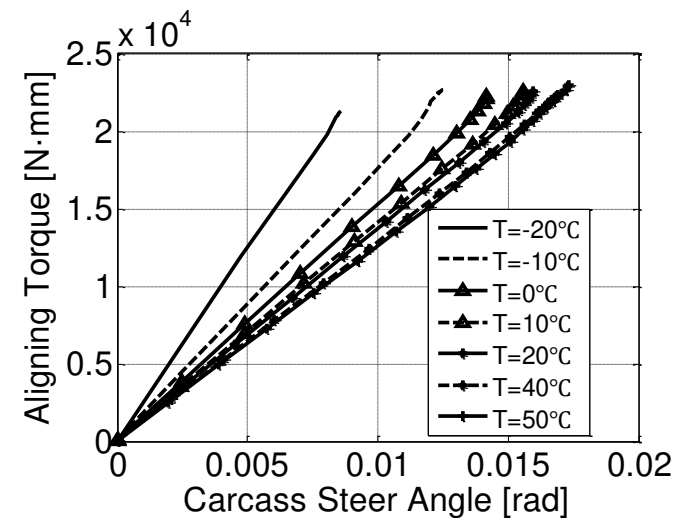

Figure 14 Aligning torque of carcass with steer angle at different temperatures ( Load $3000 \mathrm{~N}$ )

It can be seen from the above results that the lateral force of the carcass gradually decreases with increasing temperature under the same load and the same lateral deformation; the aligning torque of the carcass gradually decreases with increasing temperature too. From the above results, extract the characteristic parameters of the lateral stiffness and torsional stiffness of the carcass as a function of temperature. As shown in Figure 15-16.

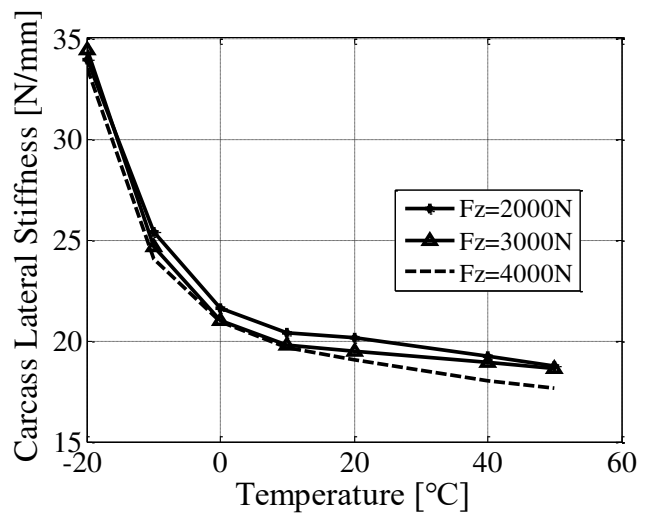

Figure15 Lateral translation stiffness of carcass with temperature

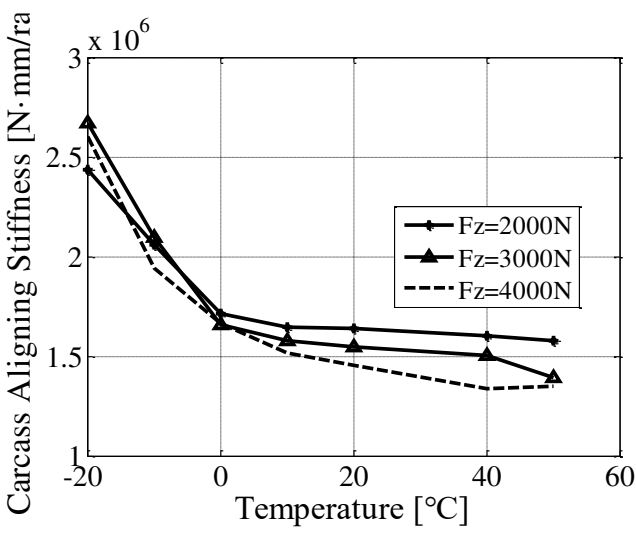

Figure16 Torsional stiffness of carcass with temperature

From the above simulation results, it can be seen that the lateral stiffness and torsional stiffness of the tire carcass gradually decrease with increasing temperature, and the curve form is close to the change form of the Exponential equation.

\section{Modeling of brush model considering tire temperature}

\subsection{Brush model considering tire temperature}

The brush model is a simplified tire physical model [13-14], which can reflect the basic mechanical characteristics of the tire. Combining the results of the above test and finite element simulation, this paper establishes a brush model considering the elasticity of the carcass [15], which includes the lateral translation deformation and the torsional deformation of the carcass as is shown in Figure 17.

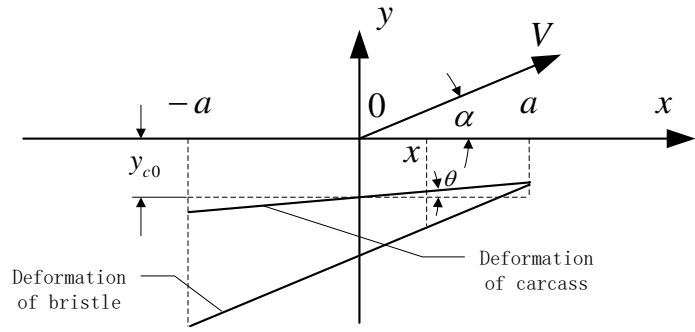

Figure17 Brush model considering the carcass elasticity

When tire side slip, according to the modelling method of brush model the expressions of the lateral force and aligning moment of the tire in the small cornering angle state can be obtained, as shown in equation (3)

$$
\left\{\begin{array}{l}
F_{y}=-2 a^{2} k_{t y} \frac{1}{\left(1+\frac{2}{3} \frac{a^{3} k_{t y}}{N_{\theta}}\right)} \operatorname{tg} \alpha=-2 a^{2} k_{t y} \frac{1}{\left(1+\varepsilon_{\theta}\right)} \operatorname{tg} \alpha \\
M_{z}=\frac{2}{3} a^{3} k_{t y} \frac{1}{\left(1+\frac{2}{3} \frac{a^{3} k_{t y}}{N_{\theta}}\right)} \operatorname{tg} \alpha=\frac{2}{3} a^{3} k_{t y} \frac{1}{\left(1+\varepsilon_{\theta}\right)} \operatorname{tg} \alpha \\
D_{x}=-\frac{1}{3} a
\end{array}\right.
$$

Define:

$$
\varepsilon_{\theta}=\frac{2}{3} \frac{a^{3} k_{t y}}{N_{\theta}}
$$

Where:

$N_{\theta}$ is the torsional stiffness of carcass

$k_{t y}$ is the bristle lateral distribution stiffness

$a$ is the length of footprint 
Thus, the expressions of tire cornering stiffness $K_{y}$ and aligning stiffness $C_{M z}$ can be obtained, as shown in equation (5)

$$
\left\{\begin{array}{l}
K_{y}=-2 a^{2} k_{t y} \frac{1}{\left(1+\varepsilon_{\theta}\right)} \\
C_{M z}=\frac{2}{3} a^{3} k_{t y} \frac{1}{\left(1+\varepsilon_{\theta}\right)}
\end{array}\right.
$$

From the test results and finite element simulation results of carcass elasticity with temperature in the previous section, we can get the variation law of the tire tread stiffness characteristics with temperature. And the formula of torsional stiffness $N_{\theta}$ with temperature is approximated as shown in equation (6)

$$
N_{\theta}=N_{\theta 0} \cdot e^{\left(p_{3}+p_{4} \cdot \frac{T}{T_{r}}\right)}
$$

Introducing this relationship into the tire brush model, we can obtain the variation characteristics of tire corner stiffness $K_{y n}$, aligning stiffness $C_{M z n}$ and pneumatic trail $D_{x n}$ considering the temperature.

According to formula (1)-formula (5), we can get:

$$
\left\{\begin{array}{l}
K_{y n}=K_{y} \cdot p_{k_{y} \text { temper }} \\
C_{M z n}=C_{M z} \cdot p_{C_{m z_{-}} \text {temper }} \\
D_{x n}=D_{x} \cdot p_{d x_{-} \text {temper }}
\end{array}\right.
$$

Define

$$
\left\{\begin{array}{l}
p_{k y_{-} \text {temper }}=e^{\left(k_{t 1}+k_{t 2} \frac{T}{T_{0}}\right)} \\
p_{C m z_{-} \text {temper }}=e^{\left(m_{t 1}+m_{t 2} \frac{T}{T_{0}}\right)} \\
p_{d x_{-} \text {temper }}=e^{\left(d_{t 1}+d_{t 2} \frac{T}{T_{0}}\right)}
\end{array}\right.
$$

where

$$
k_{t 1}, k_{t 2}, m_{t 1}, m_{t 2}, d_{t 1}, d_{t 2} \text { are the temperature }
$$

parameters

Combining formula (7) and formula (3), we can get the expressions of tire lateral force, aligning torque and pneumatic trail at different temperatures, as shown in formula (9):

$$
\left\{\begin{array}{l}
F_{y}=-K_{y 0} \cdot e^{\left(k_{t 1}+k_{t 2} \frac{T}{T_{0}}\right)} \cdot \operatorname{tg} \alpha \\
M_{z}=C_{M z 0} \cdot e^{\left(m_{t 1}+m_{t 2} \frac{T}{T_{0}}\right)} \cdot \operatorname{tg} \alpha \\
D_{x}=D_{x 0} \cdot e^{\left(d_{t 1}+d_{t 2} \frac{T}{T_{0}}\right)}
\end{array}\right.
$$

According to formula (9), the brush model considering the tire temperature is used to simulate the tire cornering conditions under small cornering angles to obtain the curves of tire lateral force and aligning torque with cornering angle under different temperatures and different vertical loads.

The simulation results of the brush model at different temperatures are shown in Figure 18-20
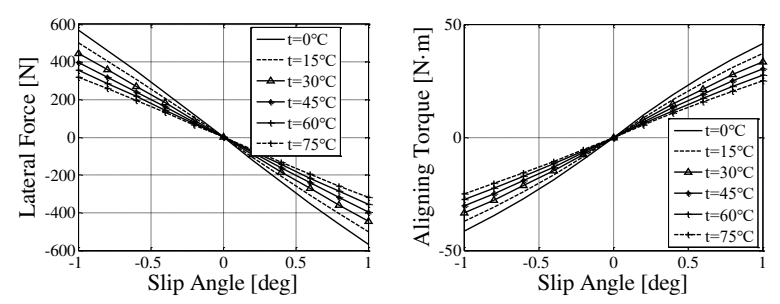

Figure 18 Lateral force and aligning torque of brush model at different temperatures under $2000 \mathrm{~N}$ vertical load
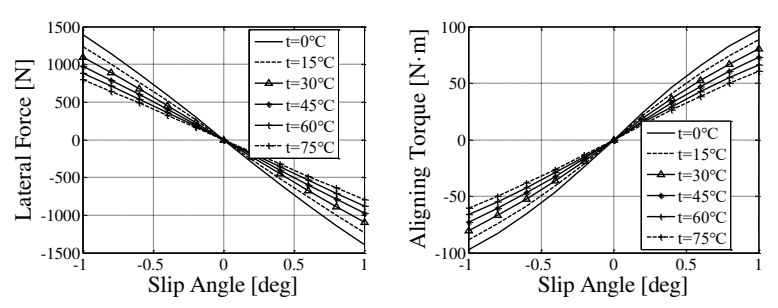

Figure 19 Lateral force and aligning torque of brush model at different temperatures under $4000 \mathrm{~N}$ vertical load 

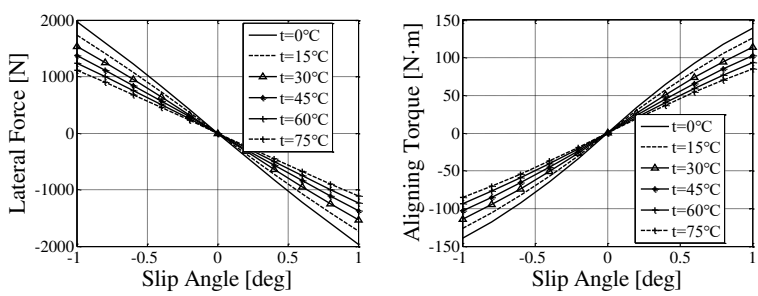

Figure 20 Lateral force and aligning torque of brush model at different temperatures under $6000 \mathrm{~N}$ vertical load

Then simulate the curve of tire cornering stiffness and aligning stiffness with tire temperature under different loads, as shown in Figure 21
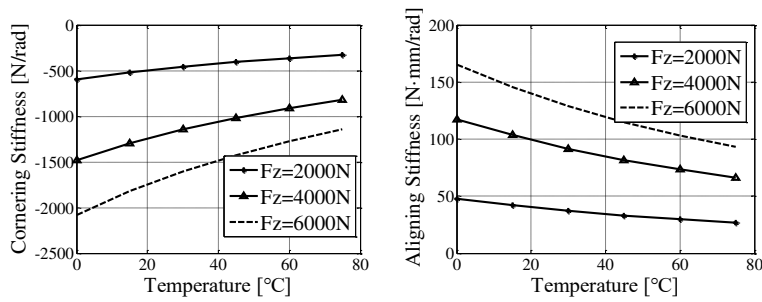

Figure 21 Lateral stiffness and aligning stiffness of the brush model with temperature under different loads

It can be seen from the above simulation results that the tire lateral force, aligning torque, cornering stiffness and aligning stiffness obtained by the brush model considering temperature are approximately the same as the rule obtained from the test.

\section{UniTire steady state model considering temperature}

UniTire model is a non-linear and non-steady-state tire model used for vehicle dynamics simulation and control. It can accurately describe the mechanical characteristics of tires under complex working conditions, and has good extension and prediction capabilities. The UniTire model can accurately express the tire characteristics of different road surfaces, tire pressures, and speeds [16-18]. However, the current research on the UniTire steady state model at different temperatures is not sufficient.

5.1 UniTire steady state cornering model considering temperature

In the tire cornering mechanical properties, the cornering stiffness and the aligning stiffness both change with the temperature of the tire. From the basic expression of UniTire [17], as shown in formula (10), it can be seen that the change of the aligning moment is determined by the lateral force and the pneumatic trail. Therefore, this paper focuses on the effect of temperature on the cornering stiffness, aligning stiffness and pneumatic trail of the tire cornering characteristics

$$
\left\{\begin{array}{l}
F_{y}=\mu F_{z}\left\{1-\exp \left[-\phi-E \cdot \phi^{2}-\left(E^{2}+\frac{1}{12} \phi^{3}\right)\right]\right\} \\
M_{z}=F_{y} \cdot D_{x} \\
D_{x}=\left(D_{x 0}-D_{e}\right) \exp \left(-D_{1} \phi-D_{2} \phi^{2}\right)+D_{e}
\end{array}\right.
$$

Where:

$\phi=\frac{K_{y} \cdot S_{y}}{\mu_{y} \cdot F_{z}}$ is the dimensionless lateral slip rate

$K_{y}$ is the cornering stiffness

According to equation (9), the relationship between temperature and tire corner stiffness is as form of the Exponential equation, so in the empirical modeling process, the relationship between temperature and corner stiffness as the Exponential equation is set as the basis for modeling. The expression of the cornering stiffness $K_{y}$ in the UniTire model is shown in equation (11), multiplied by $K_{y_{-} \text {tempe }}$, and its expression formula is shown in equation (12). Finally, the expression of the lateral stiffness model of the UniTire model considering the influence of temperature is finally obtained, as shown in formula (13);

$$
\begin{gathered}
K_{y}=s_{11} \cdot F_{z} \cdot \operatorname{sech}\left(s_{12} \cdot F_{z n}^{2}+s_{13} \cdot F_{z n}\right) \cdot\left(1-s_{14} \cdot \sin ^{2} \gamma\right)(11) \\
K_{y_{-} \text {tempe }}=k_{t 1} \cdot e^{\left(k_{t 2}+k_{t 3} \cdot \frac{T}{T_{0}}\right)} \\
K_{y}=s_{11} \cdot F_{z} \cdot \operatorname{sech}\left(s_{12} \cdot F_{z n}^{2}+s_{13} \cdot F_{z n}\right) \cdot\left(1-s_{14} \cdot \sin ^{2} \gamma\right) \cdot K_{y_{-} \text {tempe }}
\end{gathered}
$$

Pneumatic trail is the ratio of aligning torque and lateral force. The change law of lateral force and aligning torque with temperature in the small slip zone is in the form of $\mathrm{E}$ exponential, so the relationship between pneumatic trail with temperature can also be set as the $\mathrm{E}$ exponential function relationship, and an empirical model is built based on this relationship. In the UniTire semi-empirical model, the pneumatic trail expression is as shown in equation (14), and multiplied by $D_{x_{-} \text {tempe }}$ on the basis of the formula, the expression is shown in (15), and the UniTire model pneumatic trail expression (16) considering the influence of temperature is obtained. 


$$
\begin{gathered}
D_{x}=\left(D_{x 0}-D_{e}\right) \exp \left(-D_{1} \phi-D_{2} \phi^{2}\right)+D_{e} \\
D_{x_{-} \text {tempe }}=d_{t 0} \cdot e^{\left(d_{t 1}+d_{t 2} \frac{T}{T_{0}}\right)} \\
\left.D_{x}=\left(\left(D_{x 0}-D_{e}\right) \exp \left(-D_{1} \phi-D_{2} \phi^{2}\right)+D_{e}\right)\right) \cdot D_{x_{-} \text {tempe }}
\end{gathered}
$$

\section{Where}

$T$ is the tire temperature

$T_{0}$ is the test tire temperature

Afterwards, UniTire model, which considers the influence of temperature, is used to identify the test data at temperatures of $0^{\circ} \mathrm{C}, 10^{\circ} \mathrm{C}, 32^{\circ} \mathrm{C}$, and $43^{\circ} \mathrm{C}$. The comparison between the identification results and the test results is shown in Figures 22-27.

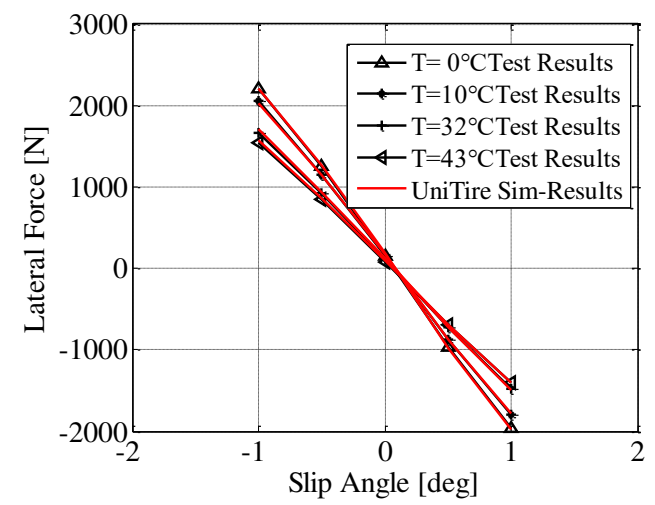

Figure22 The comparison results of the lateral force between identification results and test results under different tire temperature at $4 \mathrm{kN}$ loads

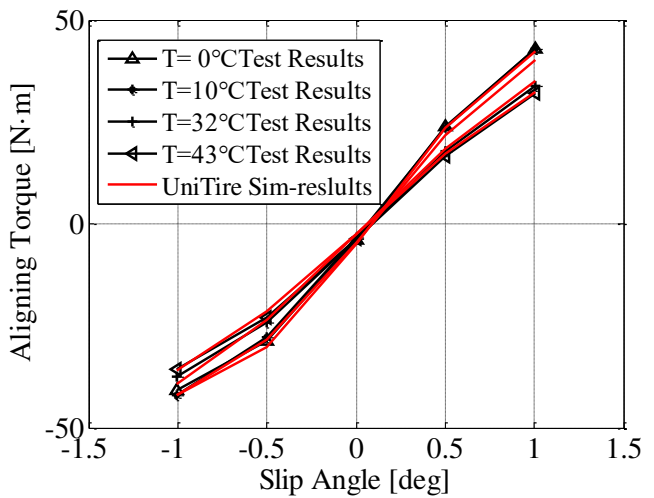

Figure 23 The comparison results of the aligning torque between identification results and test results under different tire temperature at $4 \mathrm{kN}$ loads

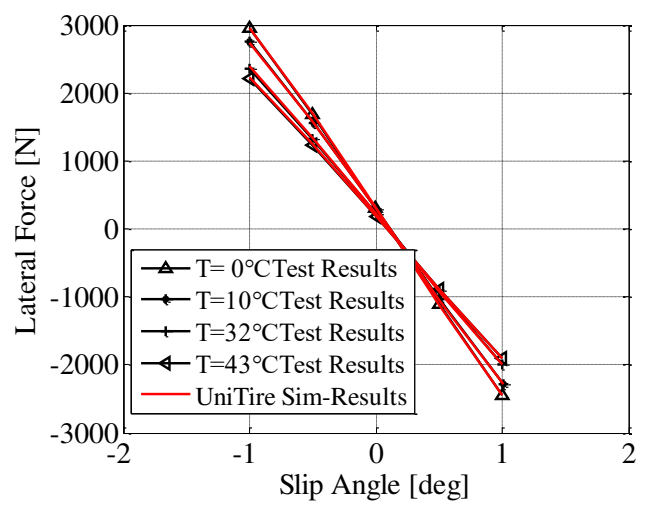

Figure24 The comparison results of the lateral force between identification results and test results under different tire temperature at $6 \mathrm{kN}$ loads

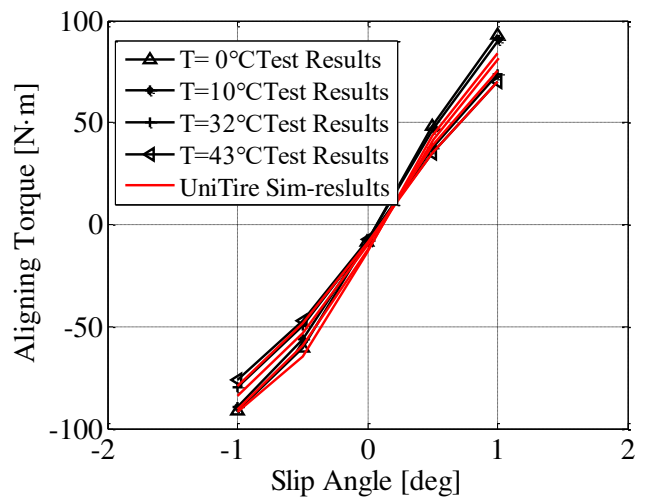

Figure 25 The comparison results of the aligning torque between identification results and test results under different tire temperature at $6 \mathrm{kN}$ loads

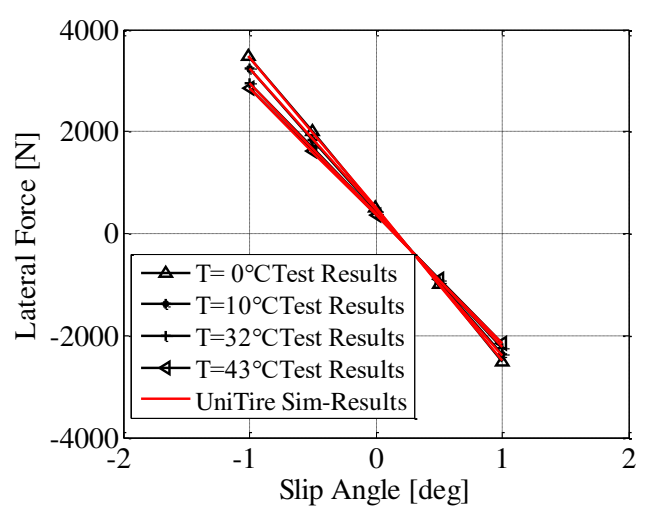

Figure26 The comparison results of the lateral force between identification results and test results under different tire temperature at $10 \mathrm{kN}$ loads 


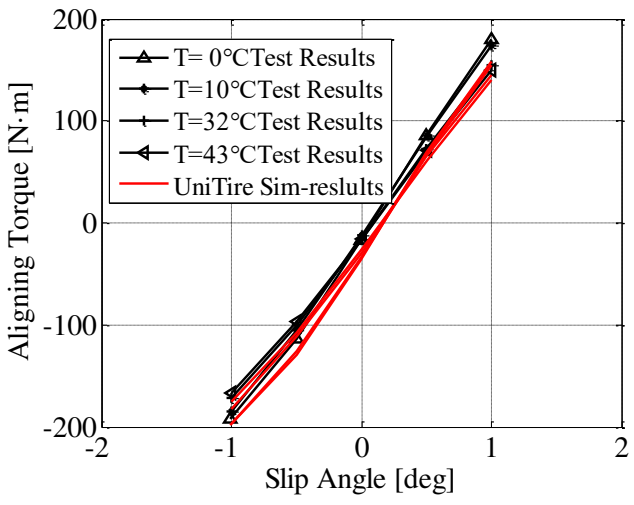

Figure 27 The comparison results of the aligning torque between identification results and test results under different tire temperature at $10 \mathrm{kN}$ loads

From the above identification results, it can be seen that the UniTire model has higher accuracy for the tire mechanical characteristics at different temperatures, and the simulationg accuracy of UniTire model is $99 \%$.

\section{2 Prediction results of UniTire cornering model at different temperatures}

The UniTire model considering temperature is obtained based on the test results at temperatures of $0^{\circ} \mathrm{C}, 10^{\circ} \mathrm{C}, 32^{\circ} \mathrm{C}$, and $43^{\circ} \mathrm{C}$. In order to verify the accuracy of the UniTire steady-state model considering temperature, the tire lateral force and aligning torque are predicted at temperatures of $18^{\circ} \mathrm{C}$ and $53^{\circ} \mathrm{C}$, the lateral force prediction results are shown in Figure 28-30, and the aligning torque prediction results are shown in Figure 31-33.

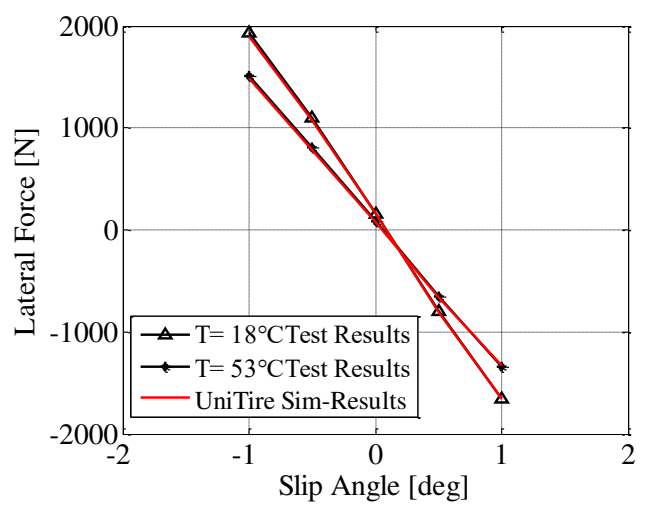

Figure 28 The comparison results of the lateral force between prediction results and test results under different tire temperature at $4 \mathrm{kN}$ loads

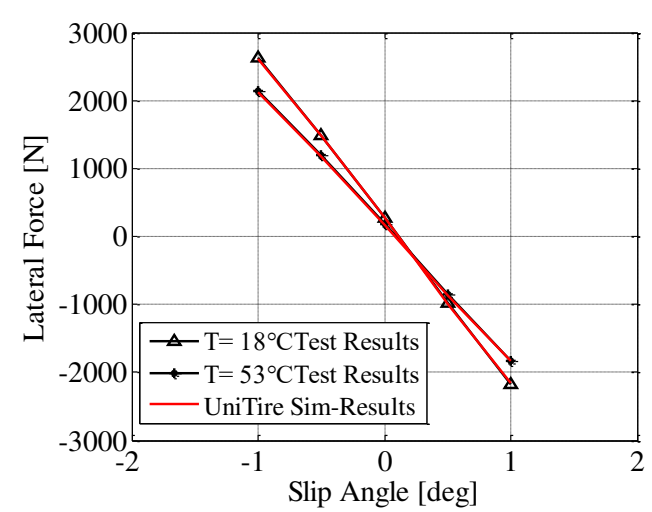

Figure 29 The comparison results of the lateral force between prediction results and test results under different tire temperature at $6 \mathrm{kN}$ loads

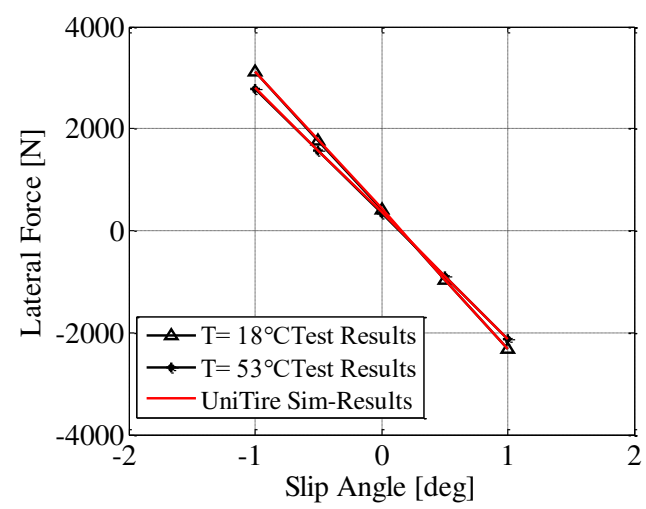

Figure 30 The comparison results of the lateral force between prediction results and test results under different tire temperature at $10 \mathrm{kN}$ loads

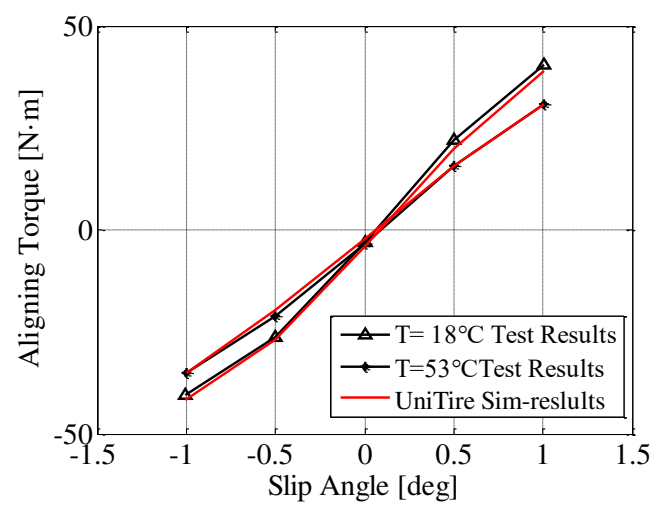

Figure 31 The comparison results of the aligning torque between prediction results and test results under different tire temperature at $4 \mathrm{kN}$ loads 


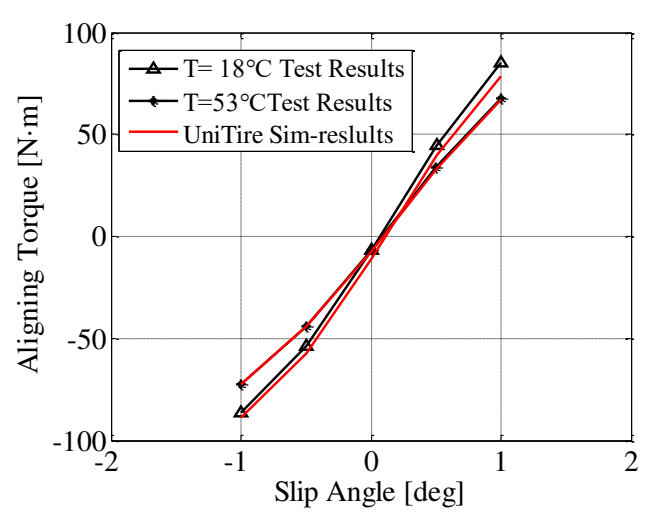

Figure32 The comparison results of the aligning torque between prediction results and test results under different tire temperature at $6 \mathrm{kN}$ loads

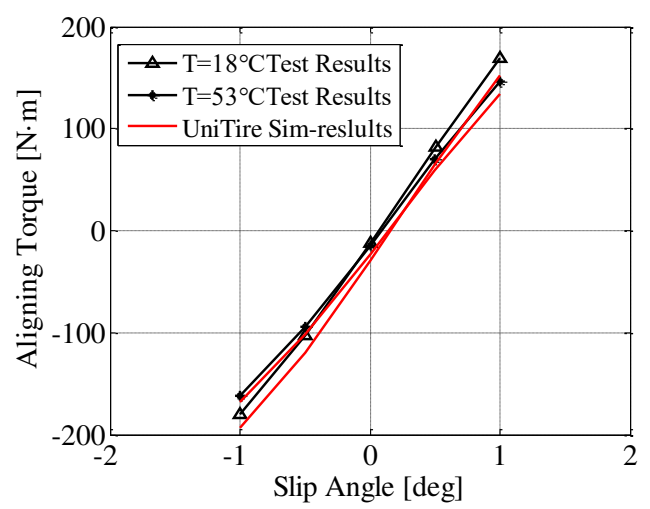

Figure 33 The comparison results of the aligning torque between prediction results and test results under different tire temperature at $10 \mathrm{kN}$ loads

From the simulation results and prediction results of the UniTire model, the prediction accuracy of the UniTire lateral force is more than $99 \%$. The accuracy of the UniTire aligning torque model is more than $96 \%$.

\section{Conclusions}

Based on the test results, the mechanical properties of tires are studied at different temperatures in this paper. The test results show that the tire cornering stiffness and aligning stiffness decreases gradually with increasing temperature. Based on the finite element analysis method and the brush model theory considering the elasticity of the carcass, a steady-state brush model of the tire considering temperature characteristics is established. The results show the trend of the basic characteristics of tire cornering with temperature, that is the tire cornering stiffness and aligning stiffness decreases gradually as the temperature increases. And the relationship between the lateral stiffness and the aligning stiffness with the temperature changes is approximately an exponential form. Finally, the UniTire tire model considering the influence of temperature is established. By comparing the simulation results and the test results, it can be seen that the UniTire cornering model considering the influence of temperature has high identification accuracy and prediction accuracy, which is of great significance for improving the UniTire model and accurately expressing the tire cornering properties under different temperature conditions.

\section{Declaration}

\section{Acknowledgements}

The authors sincerely thanks to Dr. Yanru Suo for his critical discussion and reading during manuscript preparation.

\section{Funding}

Supported by National Natural Science Foundation of China (Grant No. 51775224),

\section{Availability of data and materials}

The datasets supporting the conclusions of this article are included within the article.

\section{Authors' contributions}

The author' contributions are as follows: Dang Lu was in charge of the whole trial; Lei Lu wrote the manuscript; Lei Lu and HaiDong Wu made a contribution to theory and test data analyses, Wei Wang and Manyi Lv assisted with sampling and laboratory analyses.

\section{Competing interests}

The authors declare no competing financial interests.

\section{Consent for publication \\ Not applicable}

\section{Ethics approval and consent to participate}

Not applicable

\section{References}

[1] RUELLAN B, Le Cam J B, JEANNEAU I, et al. Fatigue of natural rubber under different temperatures[J]. International Journal of Fatigue, 2018.

[2] DONG Y, YAO X , YAN H, et al. Macro- and mesoscopic 
mechanical properties of complex fabric rubber composite under different temperatures[J]. Composite Structures, 2019, 230:111510.

[3] WEI Yintao, LIU Yuyan, DU Xingwen, et al. Non-linear FEA of rolling resistance and temperature profile for radial tire[J]. Tire Industry. 1998(06):10-15.

[4] LI Youde, ZHAO Ziliang, WANG Qingnian, et al. Non-steady state termal analysis on temperature field of a rolling automobile tire at high speed[J]. Automotive Engineering. 2002, 024(001):60-64.

[5] LI Jie, WANG Qingnian, ZHAO Ziliang, et al. A numerical research on temperature field distribution in steady state for a high-speed rolling tire[J] Automotive Engineering. 2003, 25(003):256-259.

[6] ROSA R D , STAZIO F D , DANIEL Giordano, et al. ThermoTyre: tyre temperature distribution during handling manoeuvres[J]. Vehicle System Dynamics, 2008, 46(9):p.831-844.

[7] Dr.-Ing. Pierre Février, Ing. Gérard Fandard. Thermal and mechanical tyre modelling for handling simulation[J]. Atz Worldwide, 2008, 110(5):26-31.

[8] MIZUNO M, SAKAI H , OYAMa K , et al. Development of a tyre force model incorporating the influence of the tyre surface temperature[J]. Vehicle System Dynamics, 2005, 43(sup1):395-402.

[9] KELLY D P, Sharp R S. Time-optimal control of the race car: influence of a thermodynamic tyre model[J]. Vehicle System Dynamics: International Journal of Vehicle Mechanics and Mobility, 2012, 50(4):641-662.
[10] CHEN Ping, Modeling on tire thermal-mechanical characteristics[D]. ChangChun, Jilin University, 2018

[11] SEOK S H, PIL J S, WON P T . Simulation of temperature rise within a rolling tire by using FE analysis[J]. Journal of Mechanical Science \& Technology, 2018, 32(7):3419-3425.

[12] LU Lei, Study on the influence of tire tread on tire vibration nosie[D]. ChangChun, Jilin University, 2017

[13] Fujioka, TAKEHIKO, and K. GODA. Discrete Brush Tire Model for Calculating Tire Forces with Large Camber Angle[J]. Vehicle System Dynamics 1996, 25(sup1):200-216.

[14] GUO K H, LIU Q. A generalized theoretical model of tire cornering properties in steady-state condition[J]. SAE Technical Paper, 1997. Vol.106:469-475

[15] XU Nan. Study on the Steady State tire model under combined conditions[J]. Jilin University. ChangChun, Jilin University, 2012

[16] GUO Konghui "UniTire: Unified Tire Model." Journal of mechanical engineering. 2016(12):90-99.

[17] GUO K H , YUAN Z C , LU D, et al. Speed prediction ability of UniTire steady-state model[J]. Journal of Jilin University (Engineering and Technology edition), 2005, 35(5):457-461.

[18] LU Dang, GUO Kong-hui. Analysis and prediction of tire cornering property for different inflation pressure. Journal of Jilin University (Engineering and Technology edition), 2011,41(04):915-920 


\section{Figures}

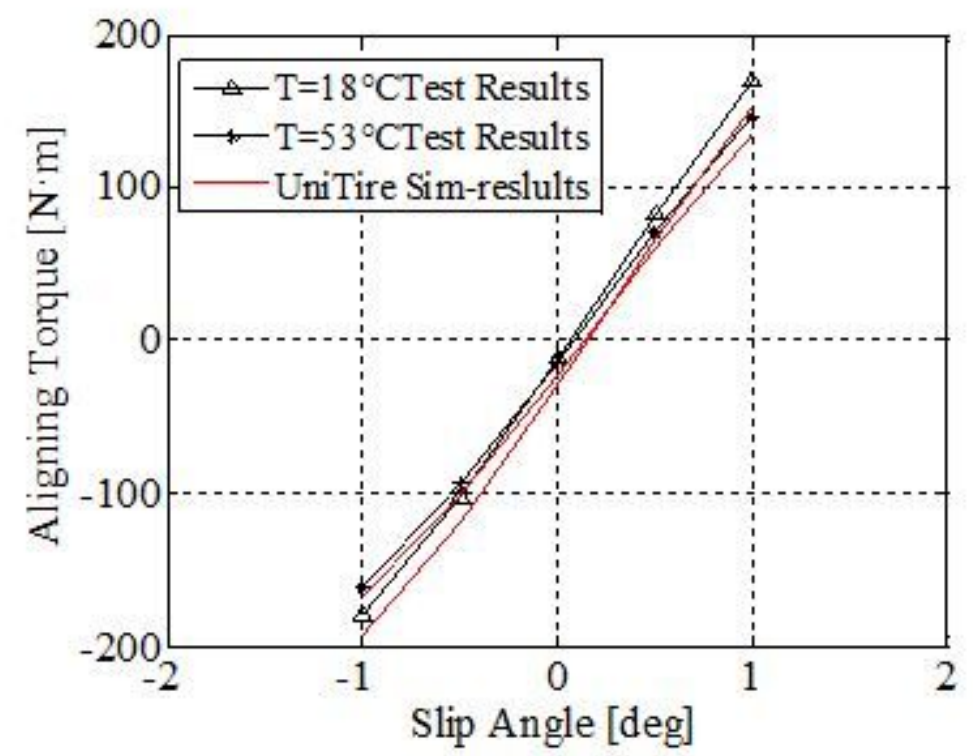

\section{Figure 1}

The comparison results of the aligning torque between prediction results and test results under different tire temperature at $10 \mathrm{kN}$ loads

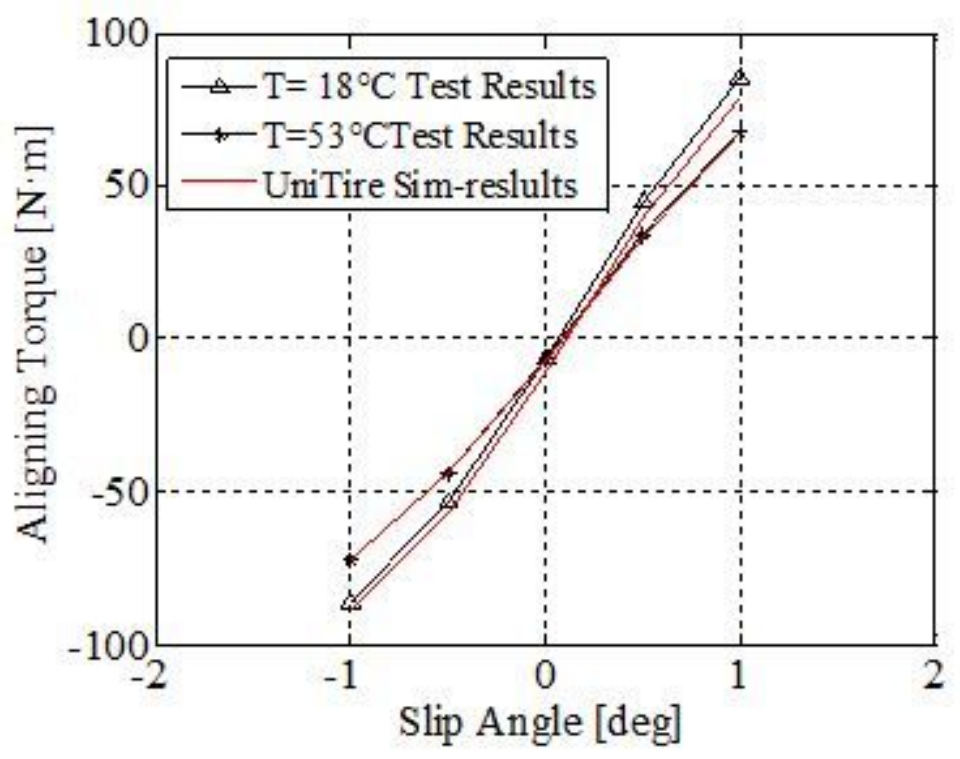

\section{Figure 2}

The comparison results of the aligning torque between prediction results and test results under different tire temperature at $6 \mathrm{kN}$ loads 


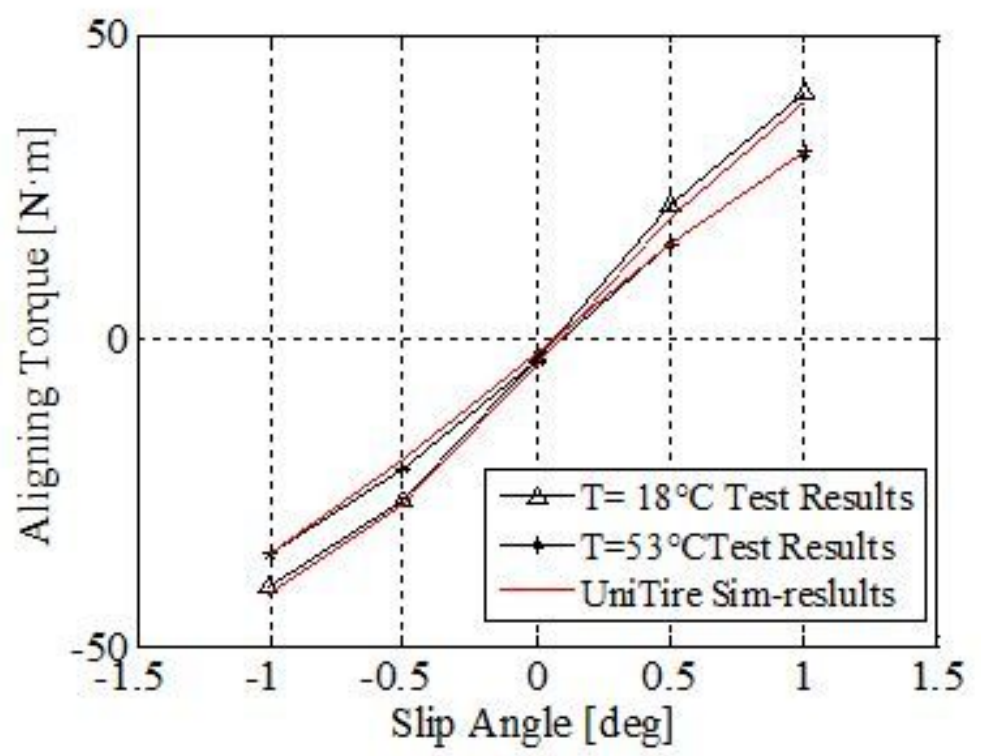

Figure 3

The comparison results of the aligning torque between prediction results and test results under different tire temperature at $4 \mathrm{kN}$ loads

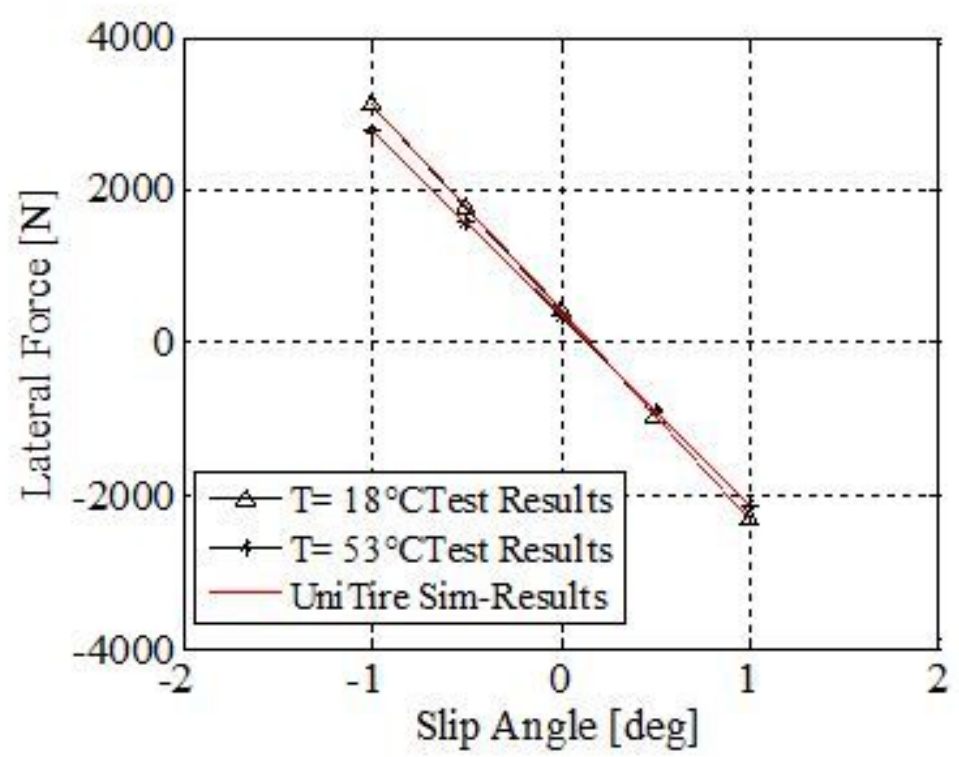

Figure 4

The comparison results of the lateral force between prediction results and test results under different tire temperature at $10 \mathrm{kN}$ loads 


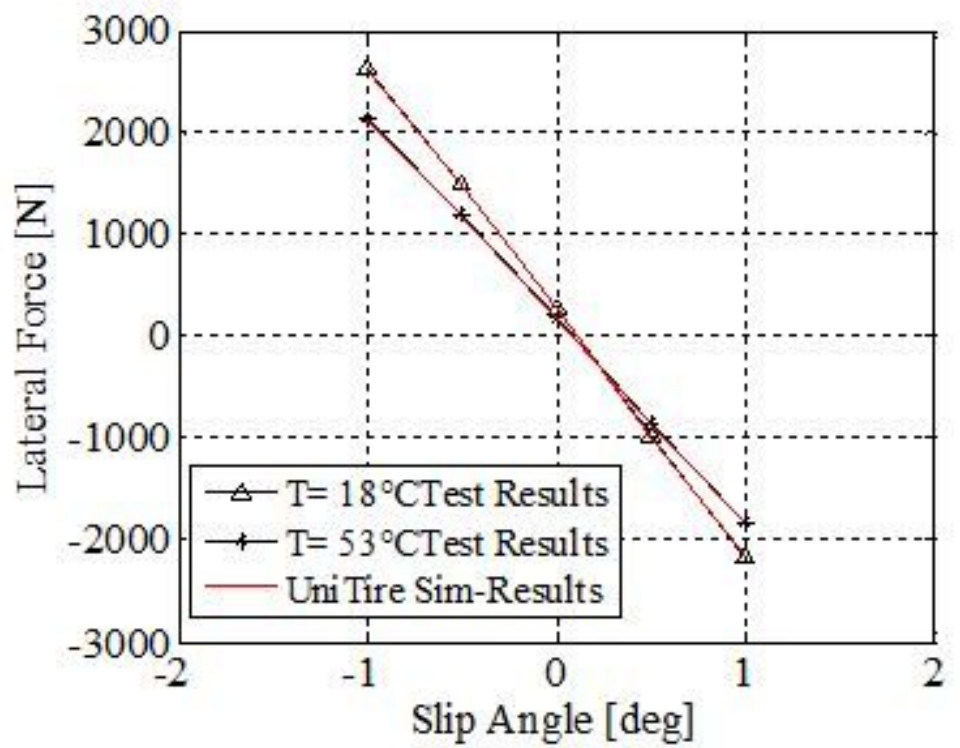

Figure 5

The comparison results of the lateral force between prediction results and test results under different tire temperature at $6 \mathrm{kN}$ loads

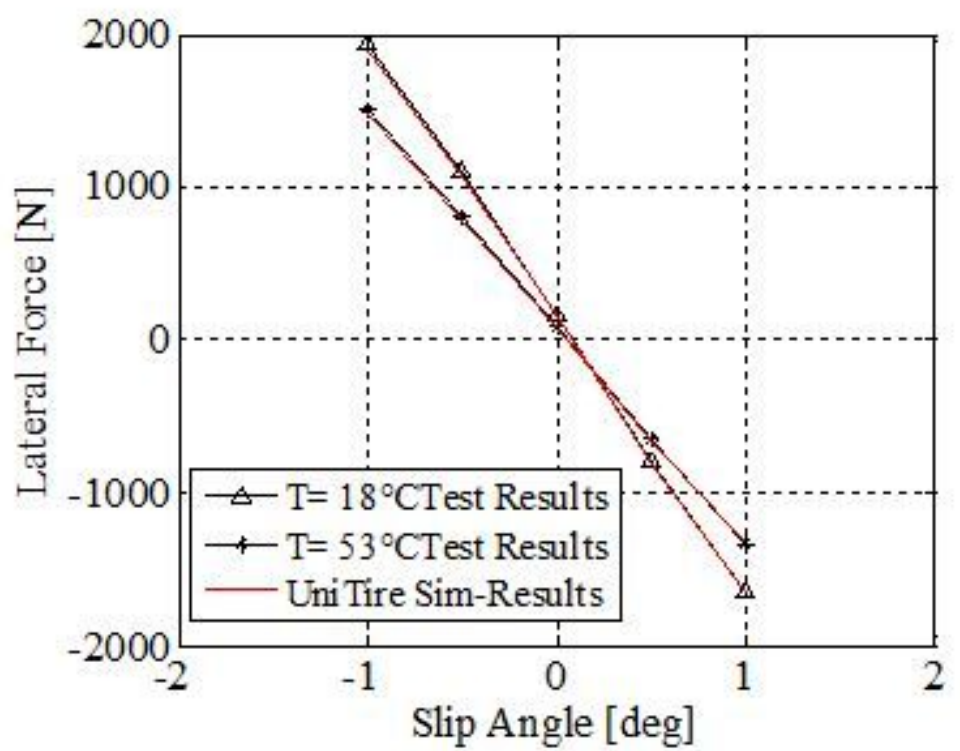

\section{Figure 6}

The comparison results of the lateral force between prediction results and test results under different tire temperature at $4 \mathrm{kN}$ loads 


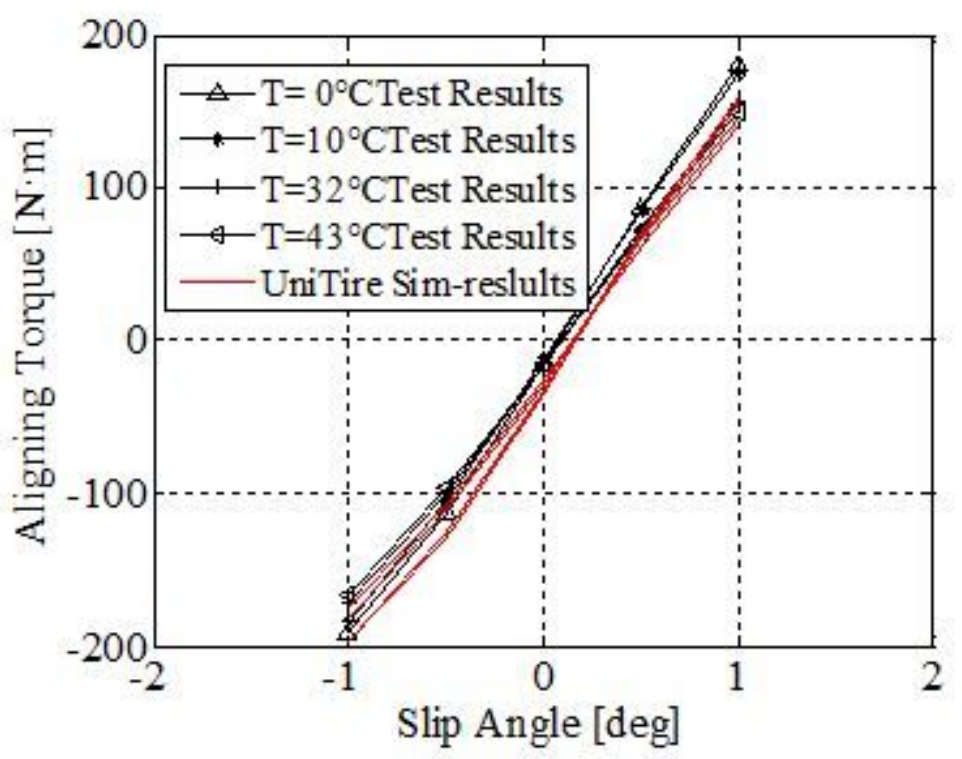

Figure 7

The comparison results of the aligning torque between identification results and test results under different tire temperature at $10 \mathrm{kN}$ loads

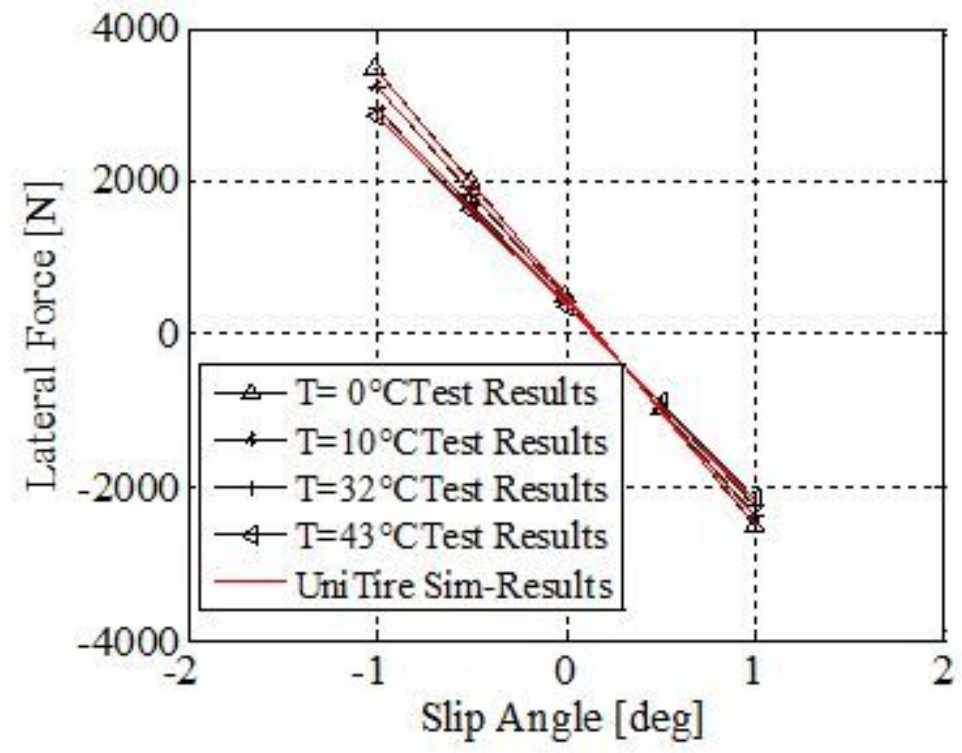

Figure 8

The comparison results of the lateral force between identification results and test results under different tire temperature at $10 \mathrm{kN}$ loads 


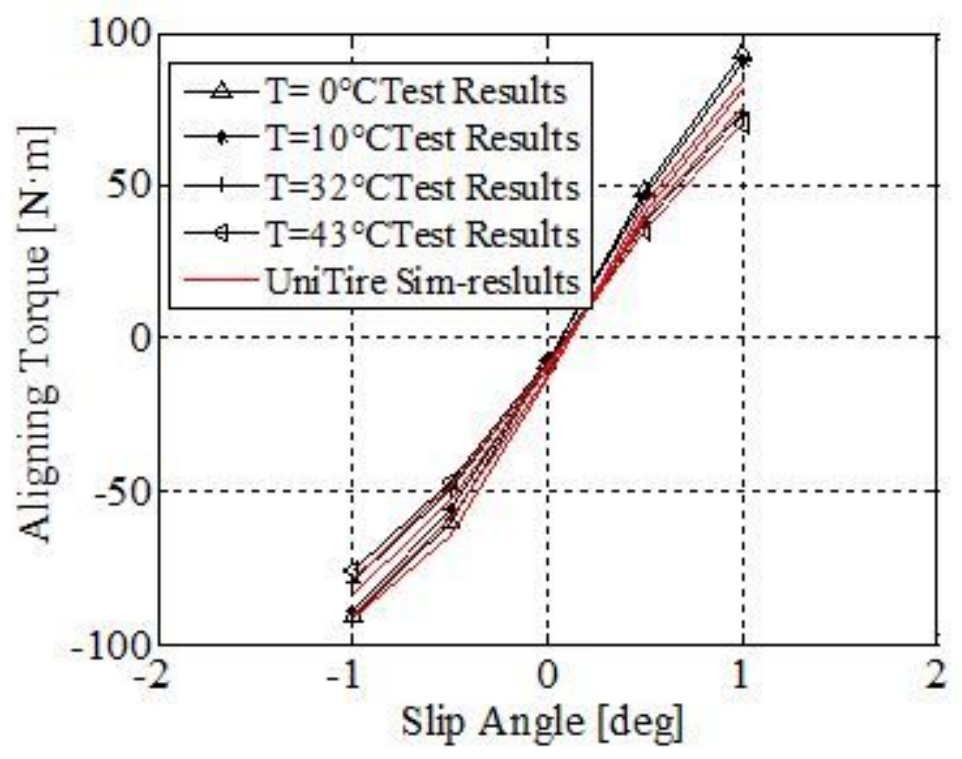

Figure 9

The comparison results of the aligning torque between identification results and test results under different tire temperature at $6 \mathrm{kN}$ loads

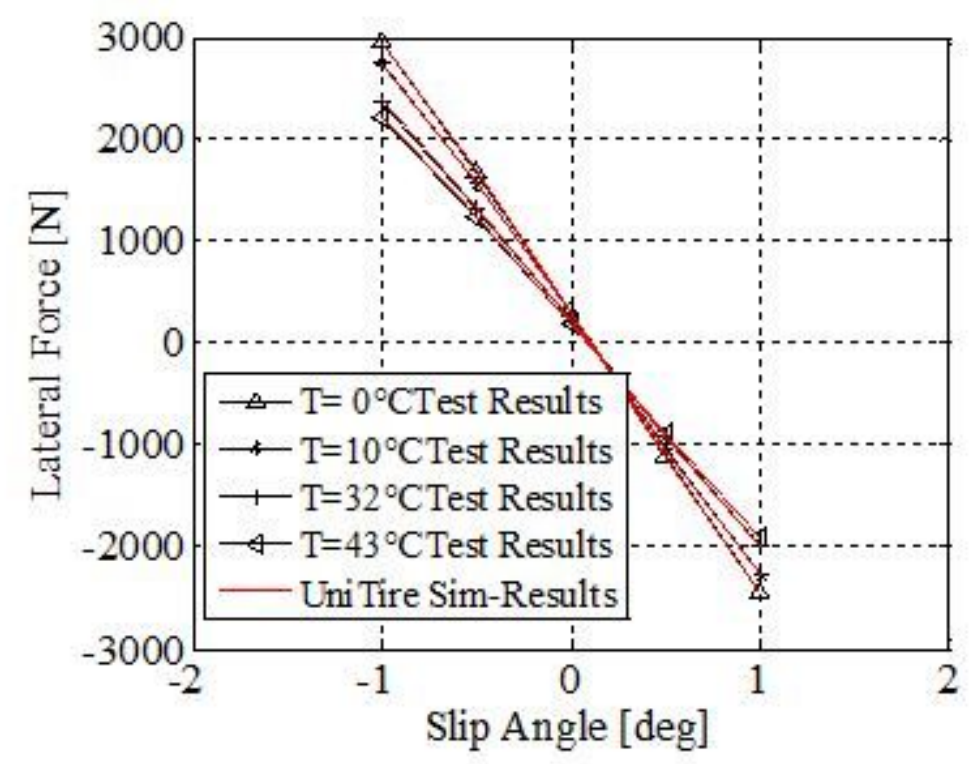

\section{Figure 10}

The comparison results of the lateral force between identification results and test results under different tire temperature at $6 \mathrm{kN}$ loads 


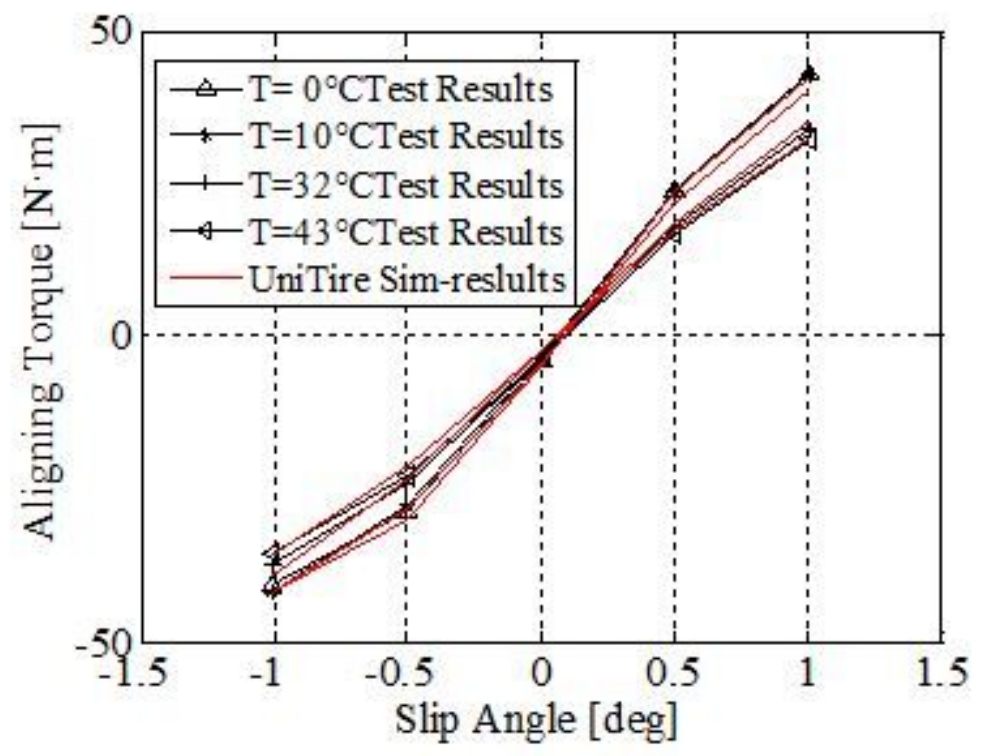

Figure 11

The comparison results of the aligning torque between identification results and test results under different tire temperature at $4 \mathrm{kN}$ loads

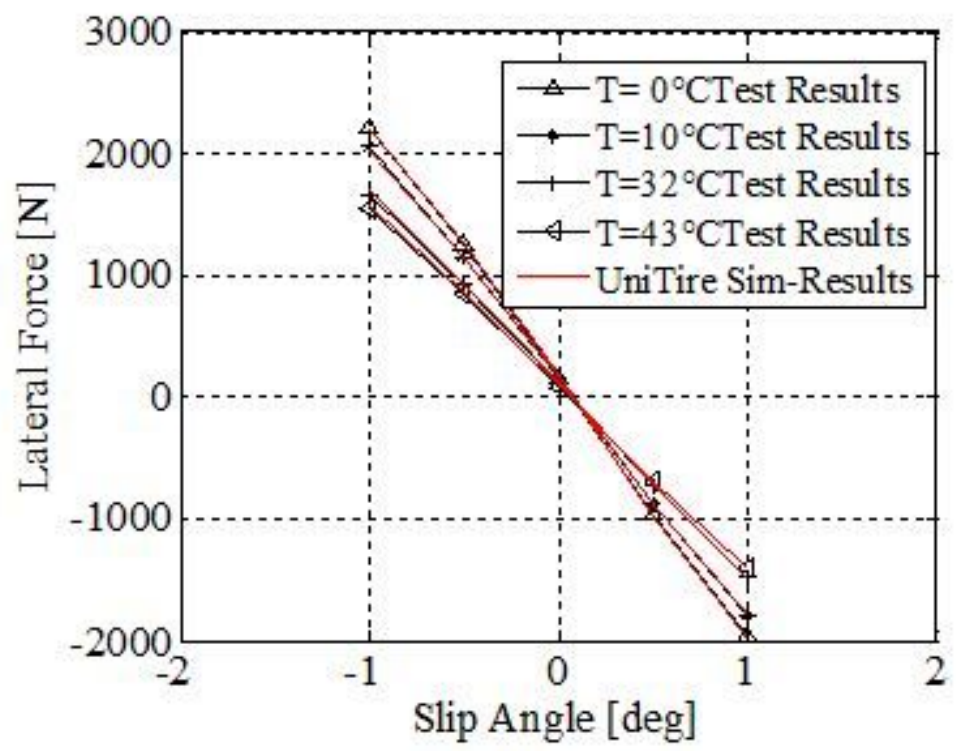

Figure 12

The comparison results of the lateral force between identification results and test results under different tire temperature at $4 \mathrm{kN}$ loads 

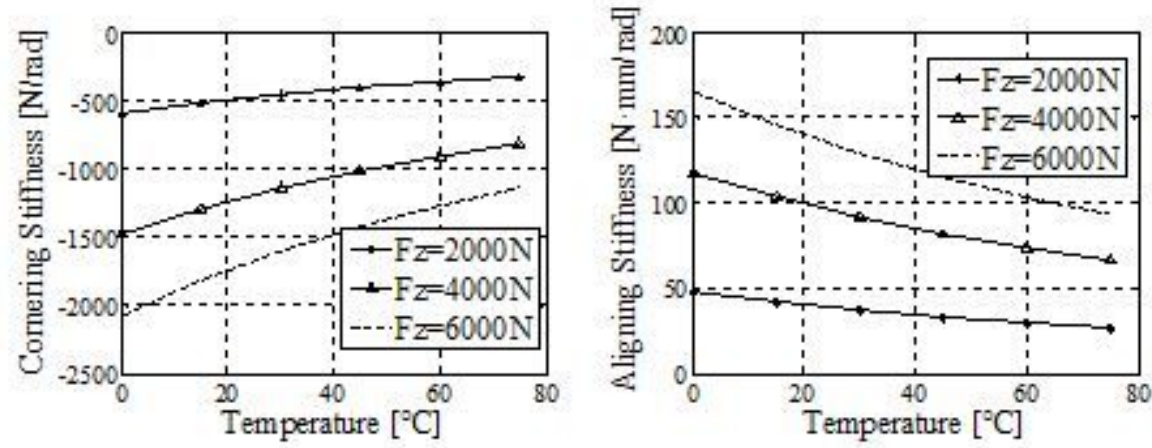

\section{Figure 13}

Lateral stiffness and aligning stiffness of the brush model with temperature under different loads
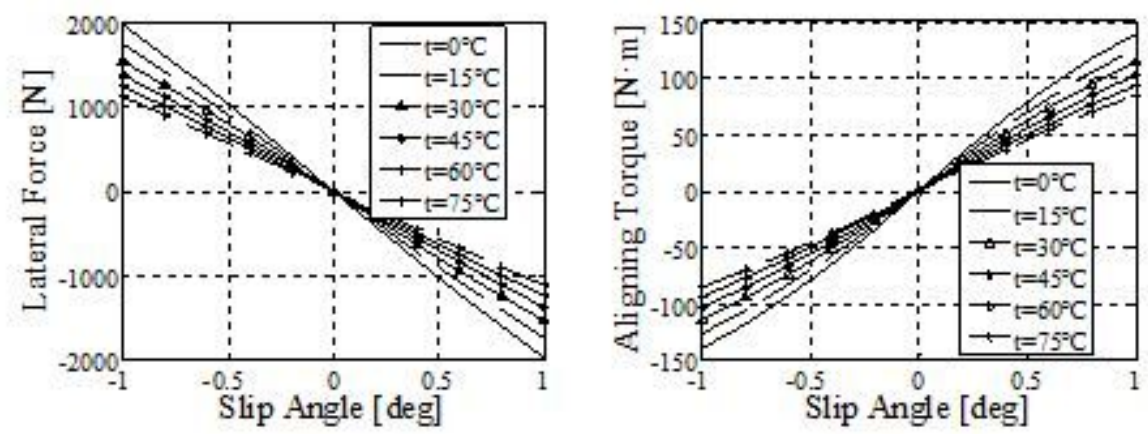

\section{Figure 14}

Lateral force and aligning torque of brush model at different temperatures under $6000 \mathrm{~N}$ vertical load
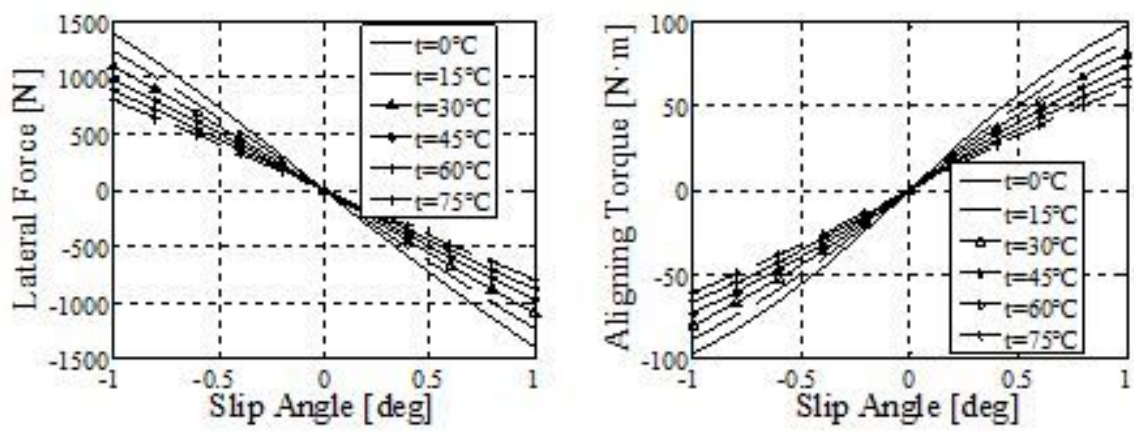

Figure 15

Lateral force and aligning torque of brush model at different temperatures under $4000 \mathrm{~N}$ vertical load 

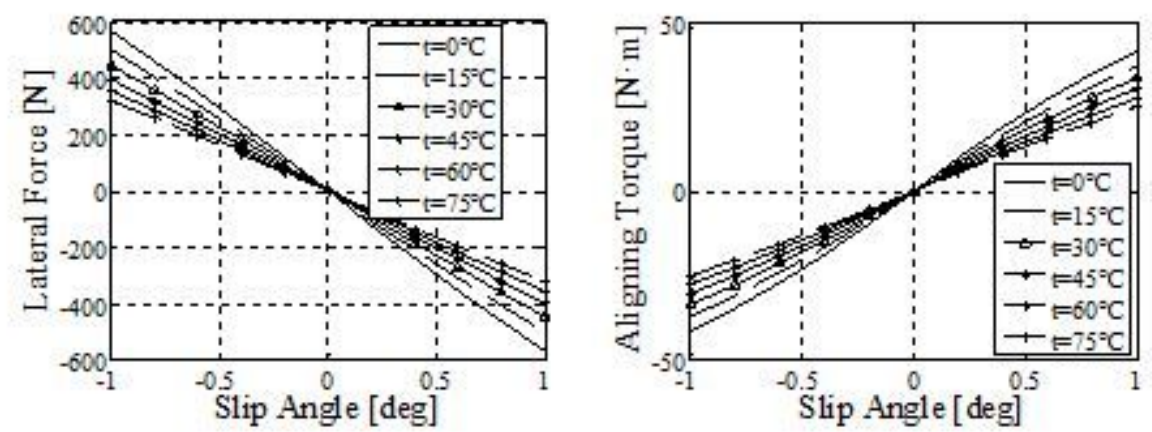

Figure 16

Lateral force and aligning torque of brush model at different temperatures under $2000 \mathrm{~N}$ vertical load

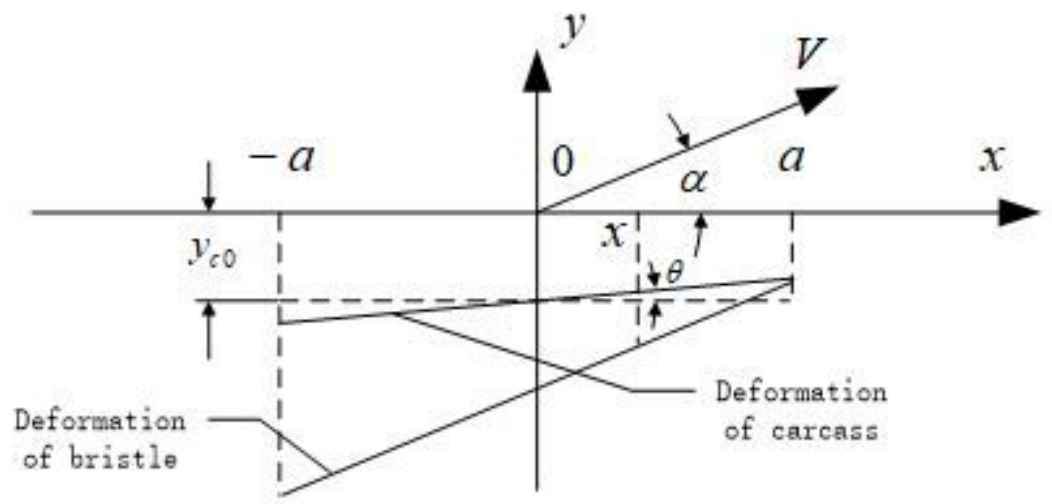

Figure 17

Brush model considering the carcass elasticity

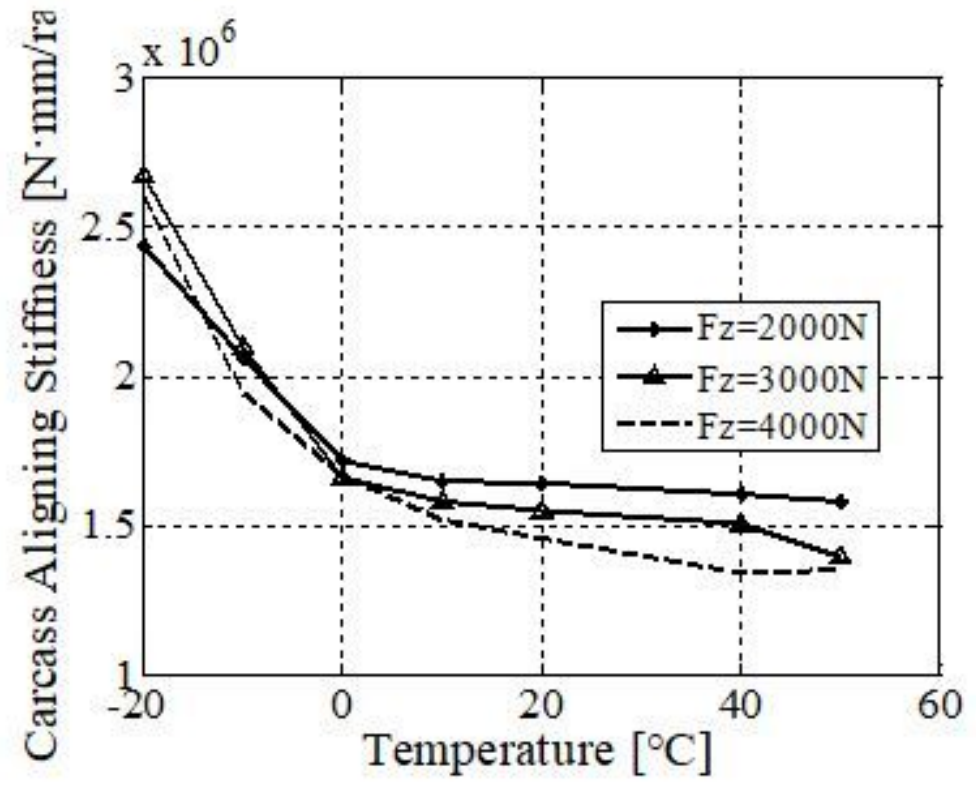

Figure 18 
Torsional stiffness of carcass with temperature

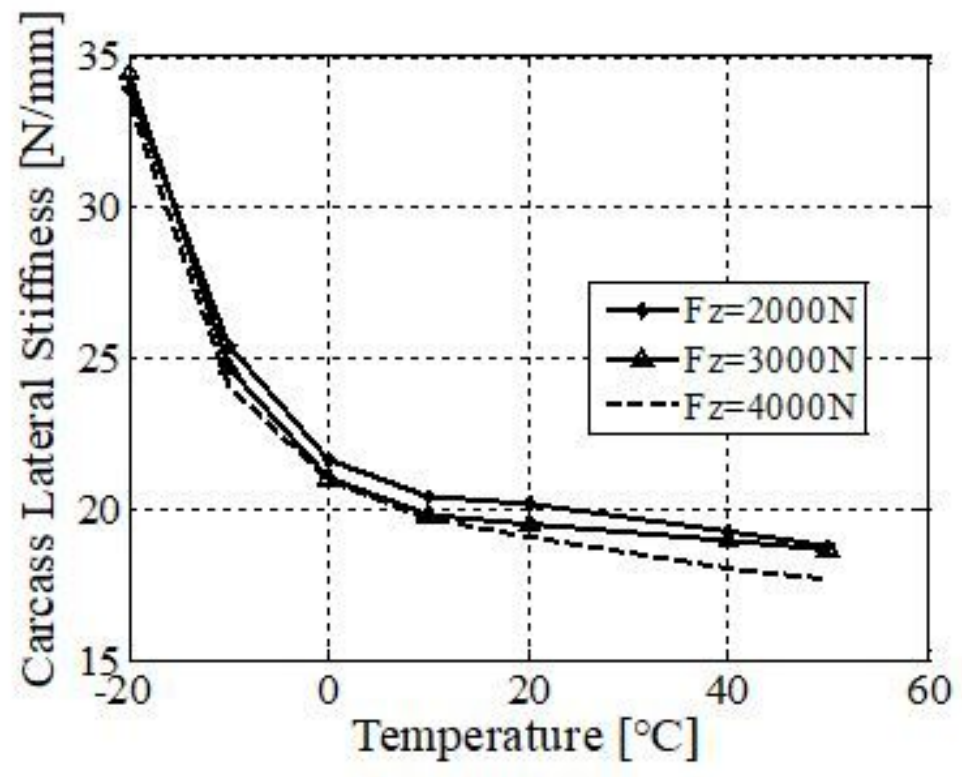

Figure 19

Lateral translation stiffness of carcass with temperature

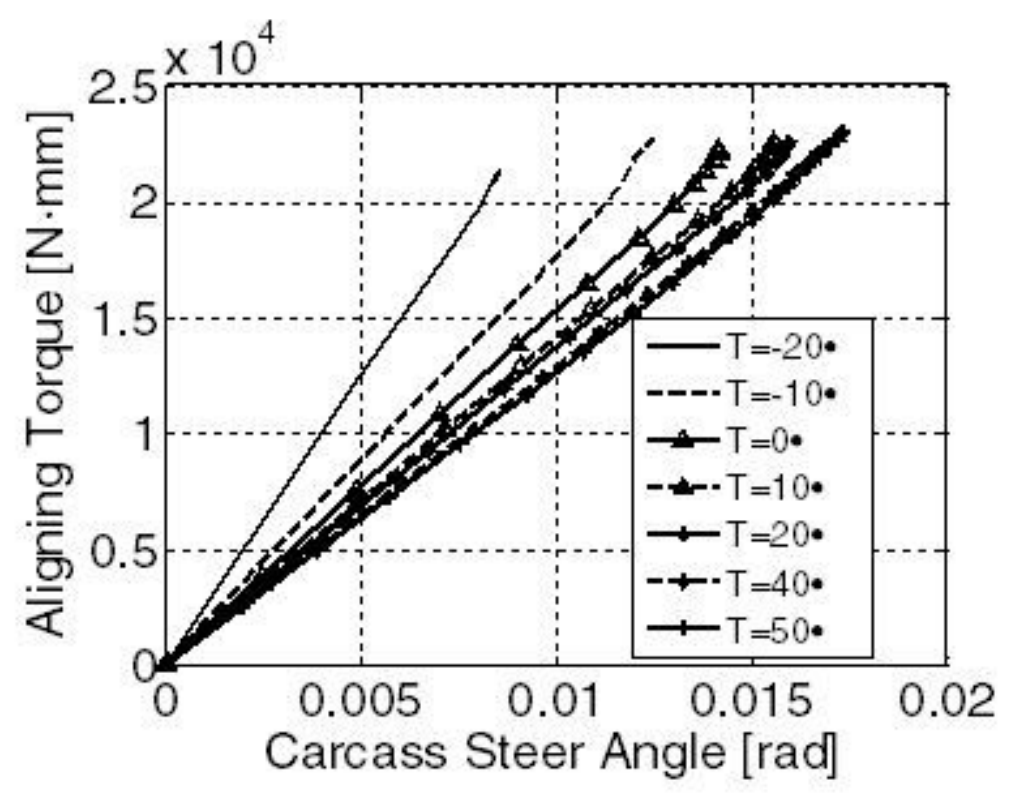

Figure 20

Aligning torque of carcass with steer angle at different temperatures $\llbracket$ Load $3000 \mathrm{~N} \rrbracket$ 


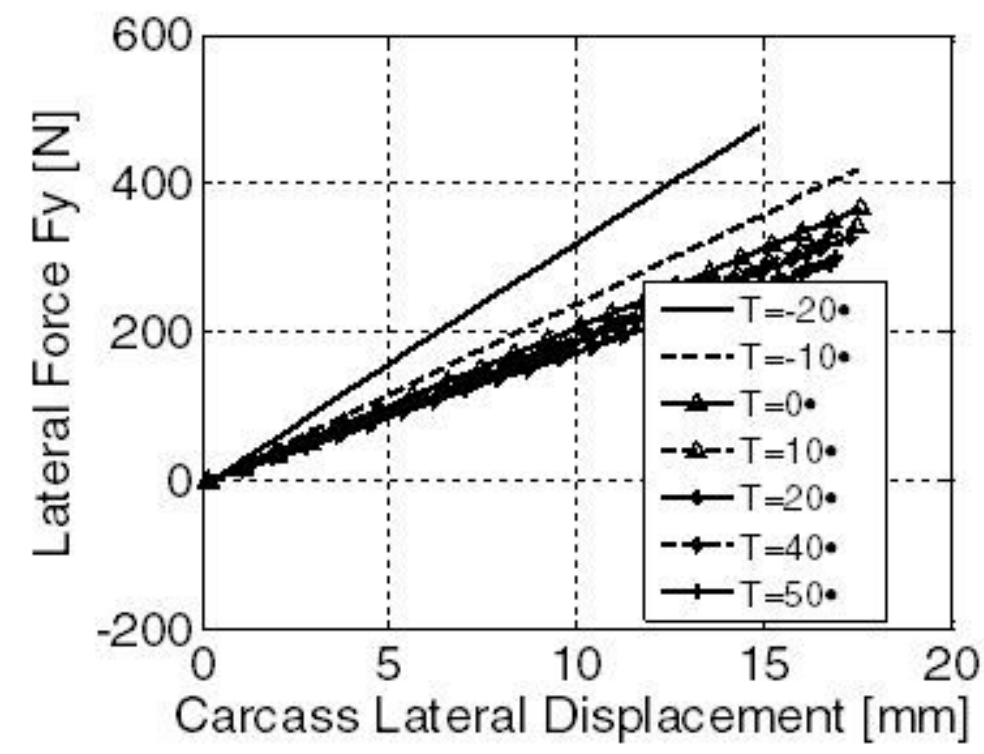

Figure 21

Lateral force of the carcass with lateral displacement at different temperatures (Load $3000 \mathrm{~N}$ )

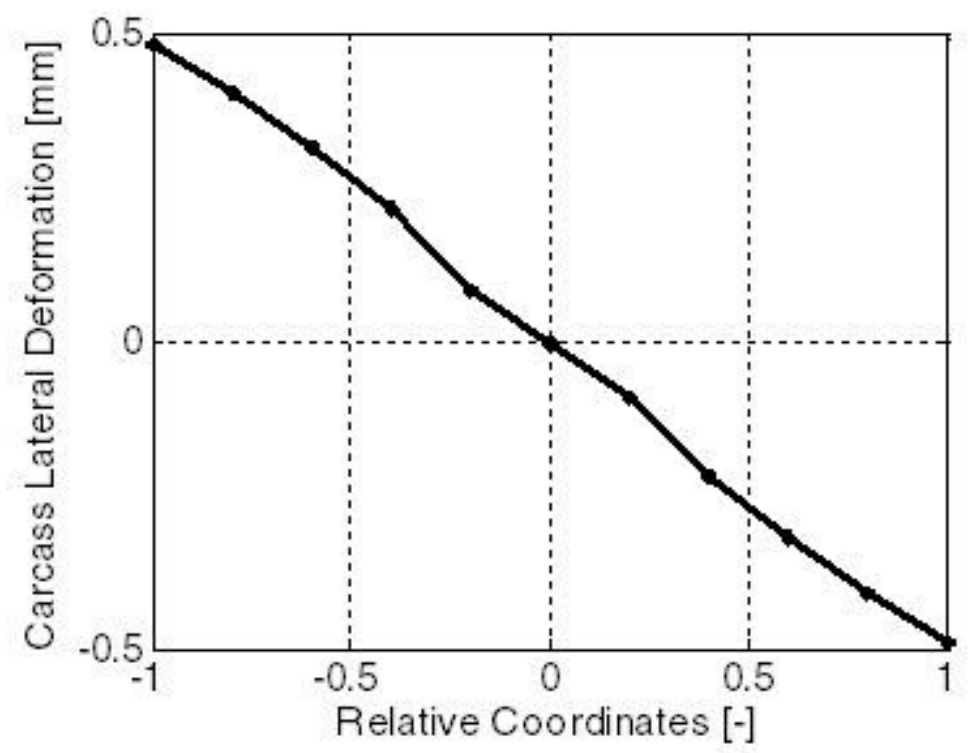

Figure 22

Deformation curve of carcass under torsional stiffness simulation 


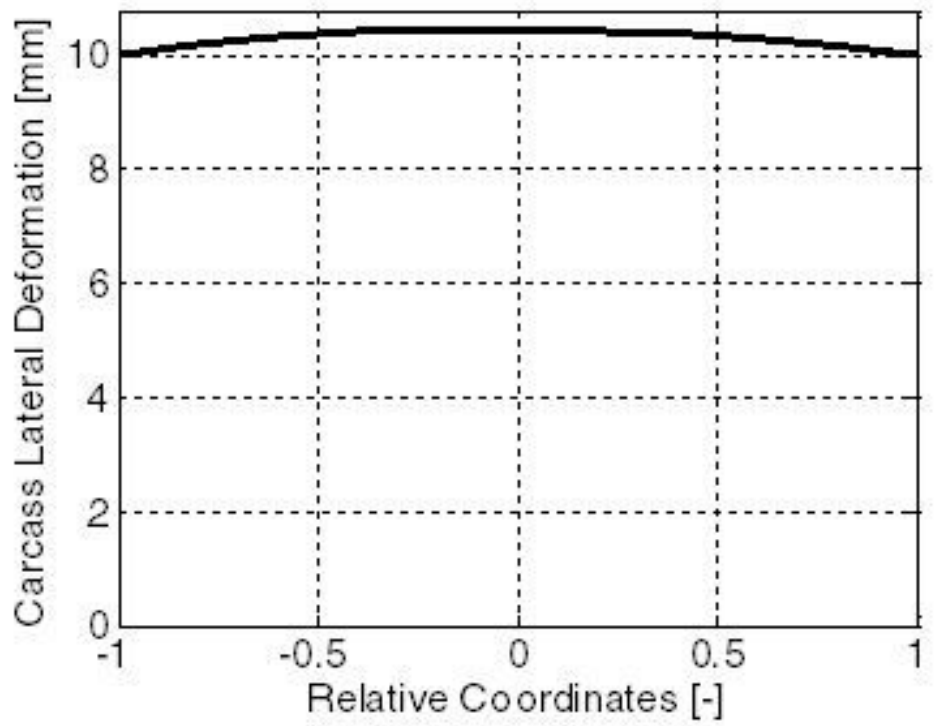

Figure 23

Deformation curve of carcass under Lateral stiffness simulation

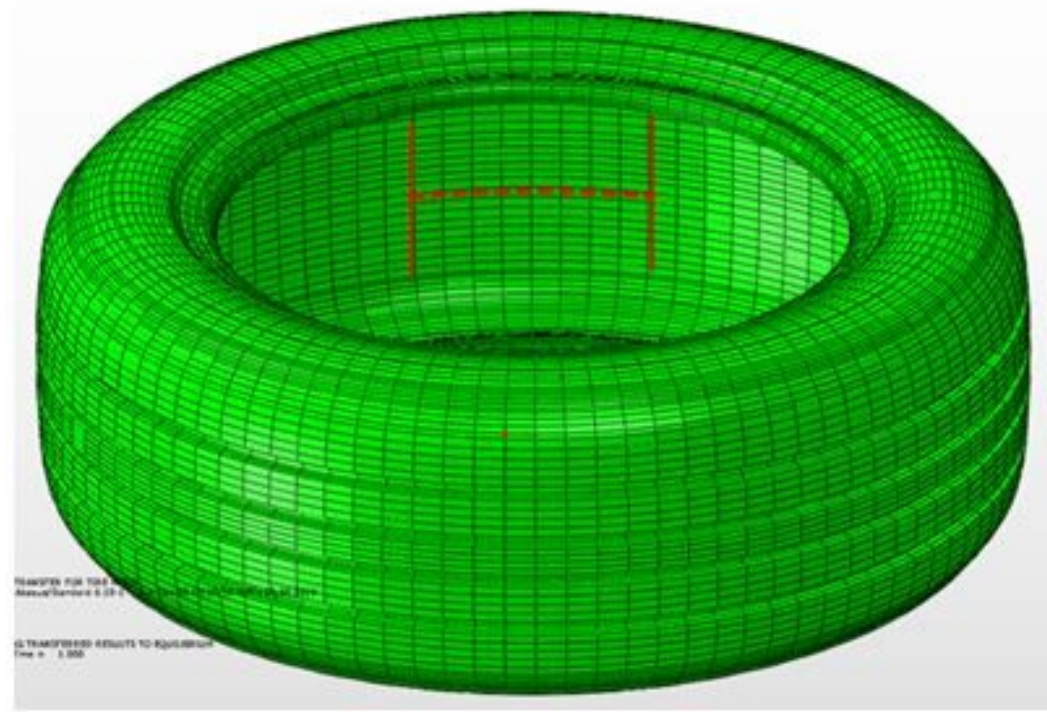

Figure 24

Node position on tire inner surface 


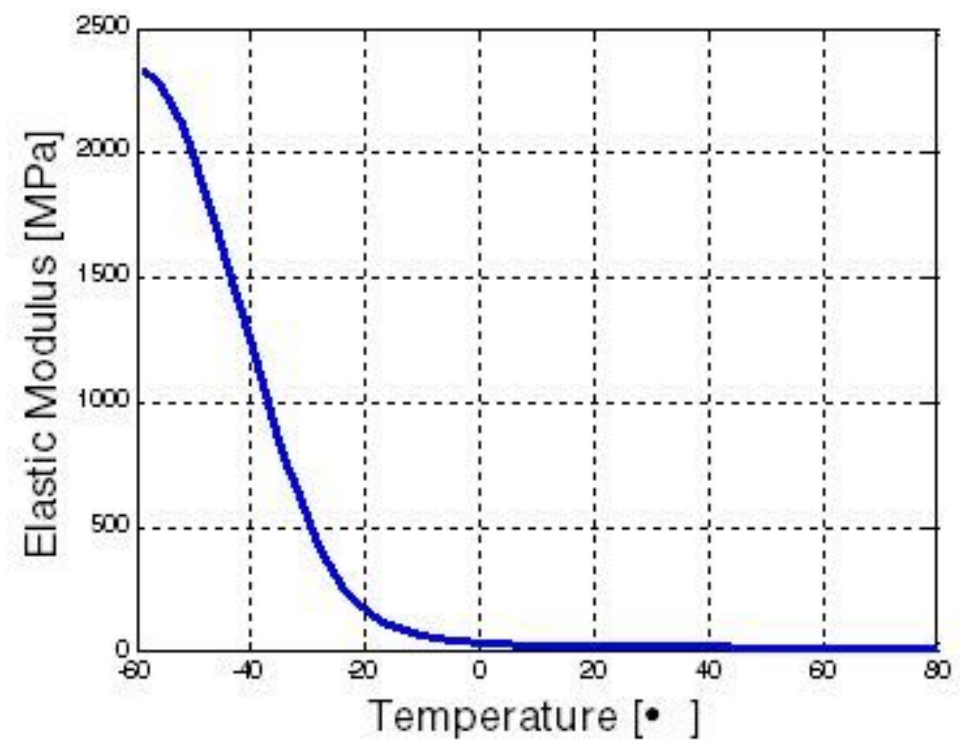

Figure 25

The elastic modulus at different temperatures

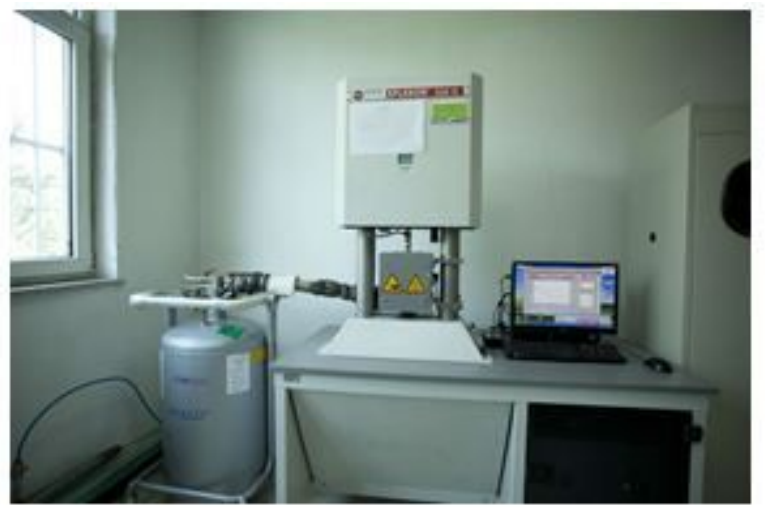

Figure 26

Rubber DMA test rig 


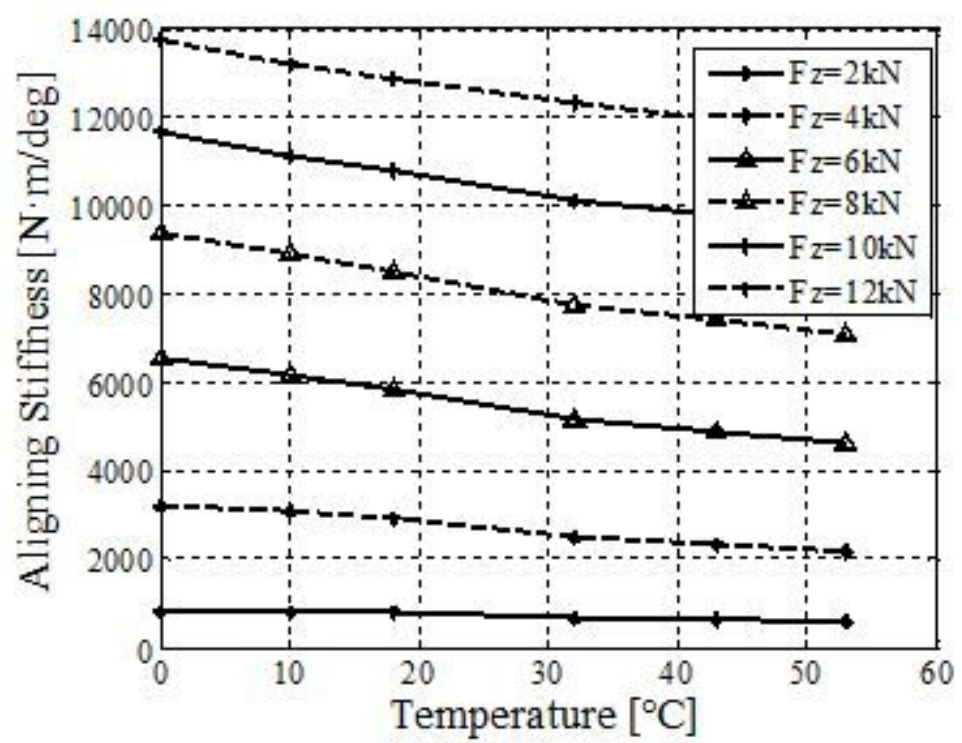

Figure 27

Variation curve of tire Aligning stiffness with temperature under different loads

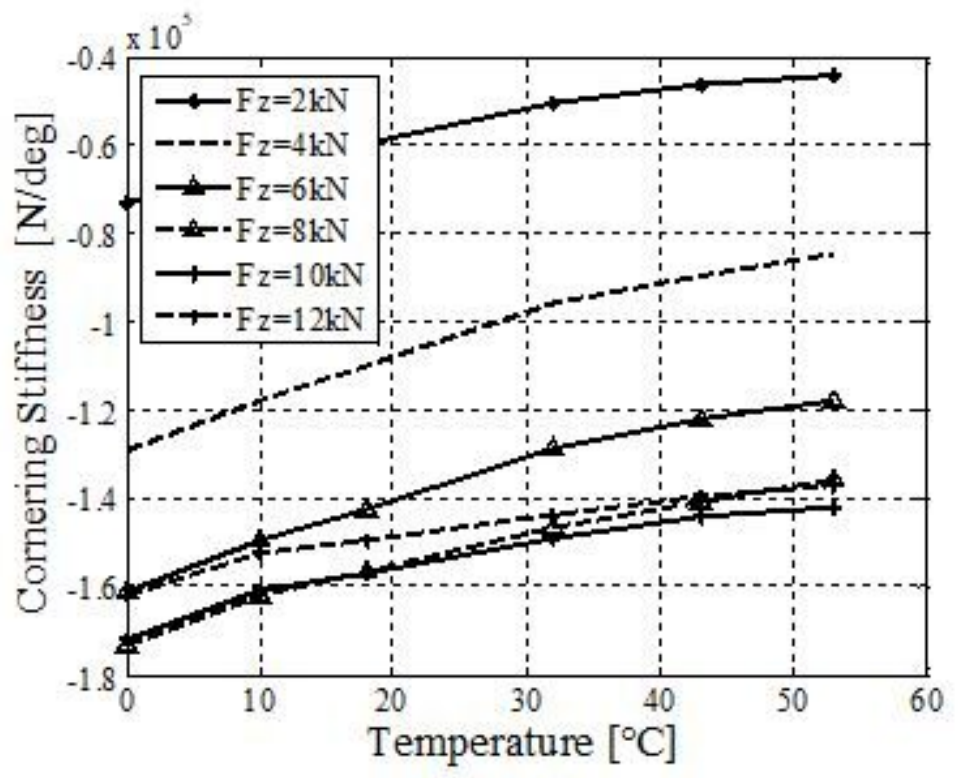

Figure 28

Variation curve of tire cornering stiffness with temperature under different loads 

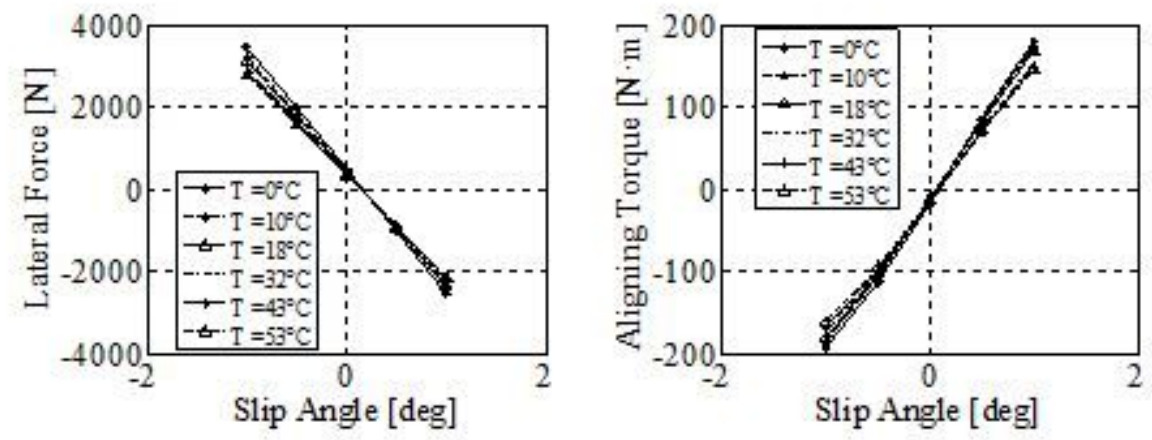

Figure 29

Comparison result of lateral force and aligning torque under different temperature at $10 \mathrm{kN}$ loads
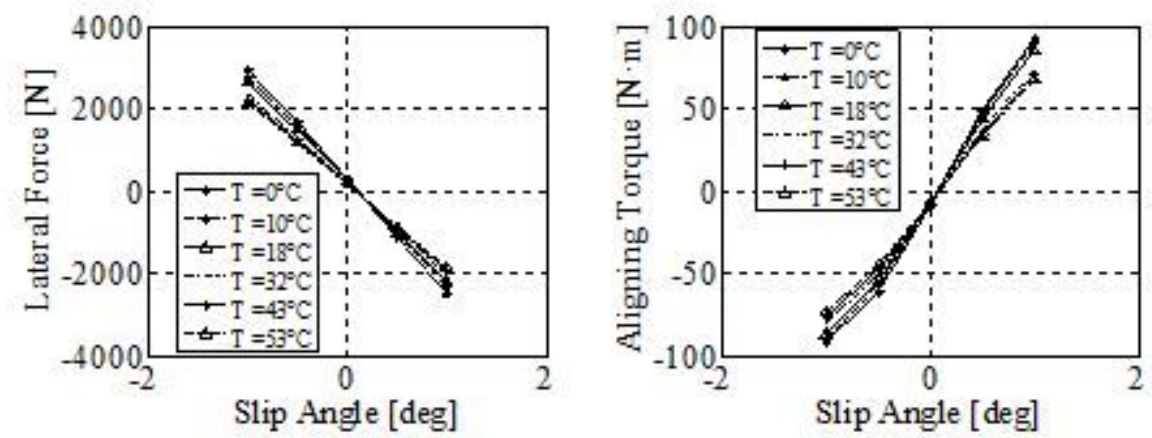

Figure 30

Comparison result of lateral force and aligning torque under different temperature at $6 \mathrm{kN}$ loads
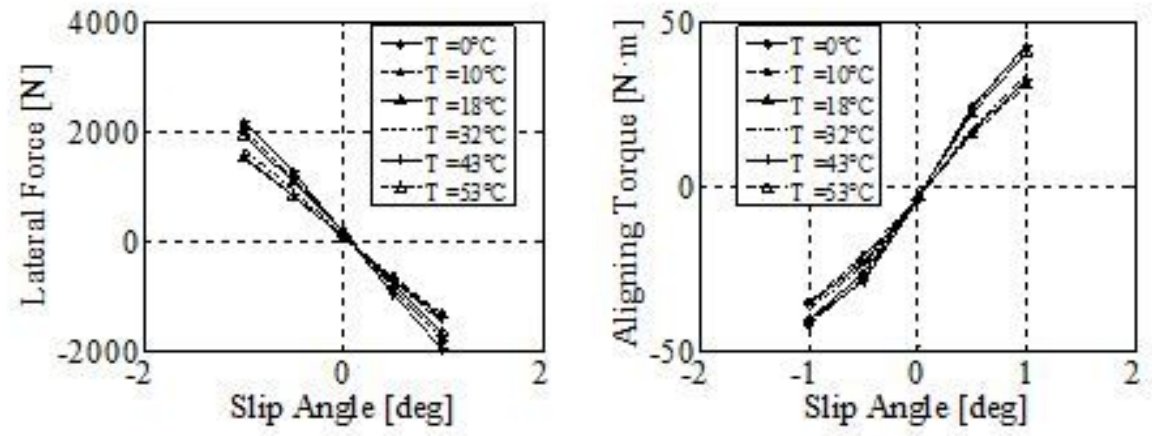

Figure 31

Comparison result of lateral force and aligning torque under different temperature at $4 \mathrm{kN}$ loads 


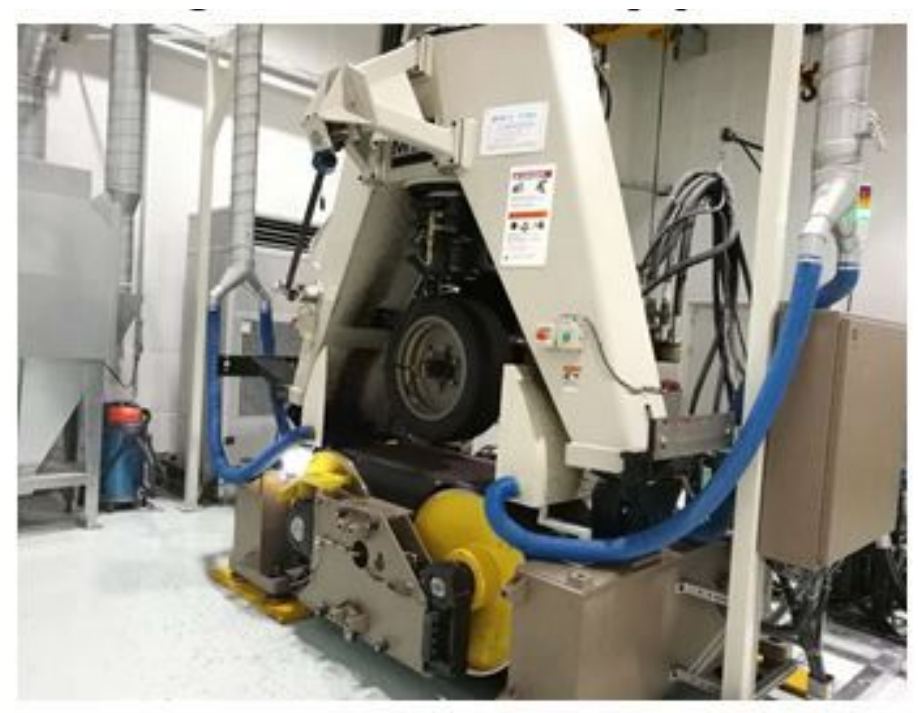

Figure 32

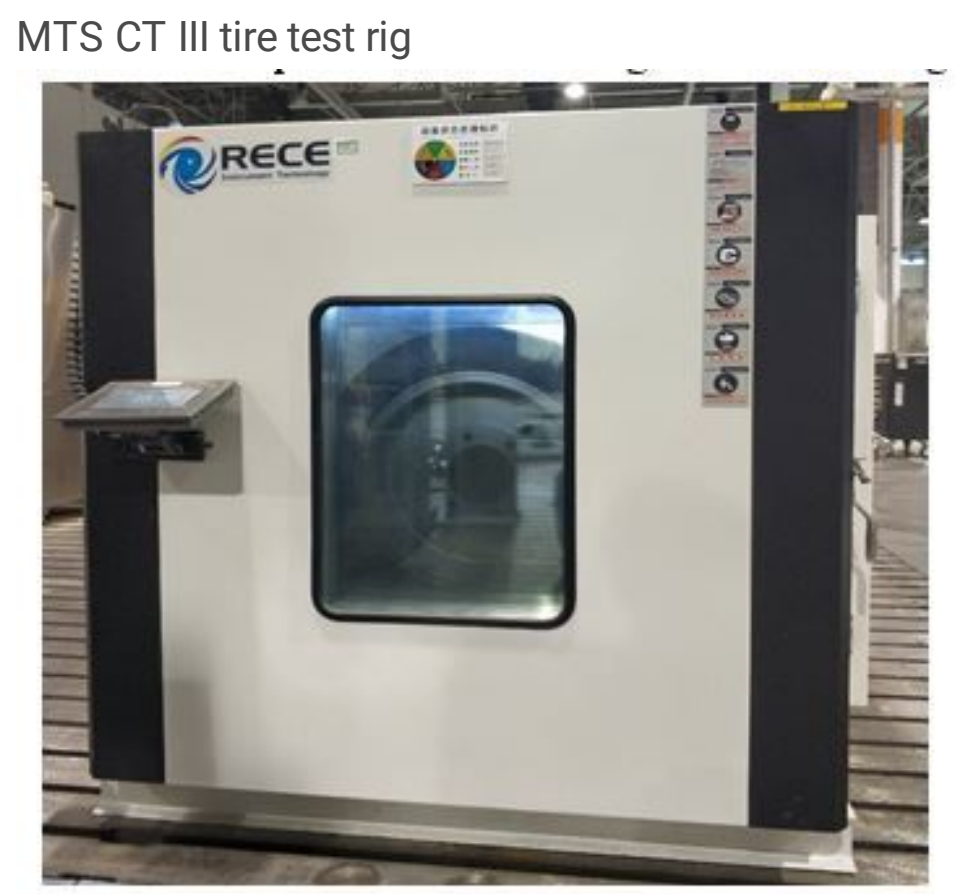

Figure 33

Tire incubator equipment 